\title{
Residual vision activation and the brain-eye-vascular triad: Dysregulation, plasticity and restoration in low vision and blindness - a review
}

\author{
Bernhard A. Sabel ${ }^{\mathrm{a}, *}$, Josef Flammer ${ }^{\mathrm{b}}$ and Lotfi B. Merabet ${ }^{\mathrm{c}}$ \\ ${ }^{a}$ Institute of Medical Psychology, Medical Faculty, Otto-von-Guericke University of Magdeburg, \\ Magdeburg, Germany \\ ${ }^{\mathrm{b}}$ Department of Ophthalmology, University of Basel, Basel, Switzerland \\ ${ }^{\mathrm{c}}$ Department of Ophthalmology, The Laboratory for Visual Neuroplasticity, Massachusetts Eye \\ and Ear Infirmary, Harvard Medical School, Boston, USA
}

\begin{abstract}
Vision loss due to ocular diseases such as glaucoma, optic neuropathy, macular degeneration, or diabetic retinopathy, are generally considered an exclusive affair of the retina and/or optic nerve. However, the brain, through multiple indirect influences, has also a major impact on functional visual impairment. Such indirect influences include intracerebral pressure, eye movements, top-down modulation (attention, cognition), and emotionally triggered stress hormone release affecting blood vessel dysregulation. Therefore, vision loss should be viewed as the result of multiple interactions within a "brain-eye-vascular triad", and several eye diseases may also be considered as brain diseases in disguise. While the brain is part of the problem, it can also be part of the solution. Neuronal networks of the brain can "amplify" residual vision through neuroplasticity changes of local and global functional connectivity by activating, modulating and strengthening residual visual signals. The activation of residual vision can be achieved by different means such as vision restoration training, non-invasive brain stimulation, or blood flow enhancing medications. Modulating brain functional networks and improving vascular regulation may offer new opportunities to recover or restore low vision by increasing visual field size, visual acuity and overall functional vision. Hence, neuroscience offers new insights to better understand vision loss, and modulating brain and vascular function is a promising source for new opportunities to activate residual vision to achieve restoration and recovery to improve quality of live in patients suffering from low vision.
\end{abstract}

Keywords: Glaucoma, optic neuropathy, recovery, plasticity, brain, vision restoration, vascular dysregulation

\section{Scope of the problem for visual impairment}

Visual impairments (VI) and blindness are among the most feared medical conditions and a

\footnotetext{
${ }^{*}$ Corresponding author: Prof. Dr. Bernhard A. Sabel, Ottovon-Guericke University, Medical Faculty, Institute of Medical Psychology, Leipziger Str. 44, 39120 Magdeburg, Germany. Tel.: +4939167 21800; Fax: +4939167 21803; E-mail: bernhard.sabel @ med.ovgu.de.
}

growing problem in our aging societies (AFB webpage; Rosenberg \& Sperazza, 2008). While visual impairment caused by diseases affecting the eye's optics (e.g. cornea and lens) can be treated by corrective lenses or surgery, there are many other causes of VI which are not typically amenable to being improved or restored, namely those caused by damage to the neural visual pathway including the retina, optic nerve $(\mathrm{ON})$, and different regions of the brain such as the thalamus, optic radiations, and visual 
cortex. These VIs vary in severity from partial (in most cases) to profound and complete blindness, impacting activities of daily living such as reading, identifying objects, orientation and mobility. And there are secondary, associated risks of psycholog$\mathrm{ical} /$ psychiatric problems such as anxiety, depression and social withdrawal (Rosenberg \& Sperazza, 2008).

The burden of low vision and blindness is immense as it impacts quality of life, cognitive function, well-being as well as society (Quigley, 2011; Chen, Bhattacharya \& Pershing, 2017). This includes employment, education opportunities, and health economics (Stevens et al., 2013). According to WHO statistics, 285 million people worldwide are visually impaired (defined as a best corrected Snellen visual acuity of $20 / 60$ or worse in the better seeing eye). Of these, 39 million are classified as blind, defined as visual acuity of 20/200 or worse in the better eye with corrective lenses, or visual field restriction of 20 degrees diameter or less in the better eye. The large majority (82\%) of individuals are aged 50 and older (Pascolini \& Mariotti, 2012; WHO Fact Sheet, 2014; Boyers et al., 2015). In developed countries, the prominent causes of VI are age-related macular degeneration (AMD; 1 to $4 \%$ ), glaucoma (2\%), diabetic retinopathy (1\%); all of which are chronic conditions with no established cures (WHO Fact Sheet 2014; Bourne, Karimkhani, Hilton, Richheimer \& Dellavalle, 2017). This is in stark contrast to the situation in developing (i.e. middle to low income) countries where $80 \%$ of visual impairment is avoidable or curable such as uncorrected refractive errors and cataracts (WHO Fact Sheet, 2014; Bourne et al., 2017).

Though modern rehabilitation strategies may help patients learn compensatory strategies to remain functionally independent (Dagnelie, 2013), little can be done to improve the vision they have lost. Therefore, new concepts and efforts are urgently needed to develop better sensory-motor compensatory and vision restoration strategies by leveraging the inherent ability of the brain to adapt to injury.

VIs following diseases of the eye (e.g. glaucoma, optic neuropathy, macular degeneration, diabetic retinopathy) are typically managed by ophthalmologists, optometrists, and other eye care professionals. In contrast, VIs associated with neurological problems are attended to by neurologists and neurosurgeons. They include diffuse brain tissue damage after stroke or traumatic brain injury, neurodegenerative diseases such as Parkinson's and other dementias, or multiple sclerosis. However, the eye and brain should not be studied, nor treated, in isolation, and effective care necessitates a combined ophthalmological and neurological approach. Specifically, the three-way reciprocal interaction of both organs with the cardio-vascular system need to be better understood. Only when appreciating the many interactions within the brain-eye-vascular triad can we fully understand and adequately modulate both the physiological and psychological state of our patients to achieve vision recovery and restoration. Though many direct causes of vision loss are well established (like ocular disease, trauma, genetic predispositions, etc.), this review paper discusses indirect factors related to the brain-eye-vascular triad and how they impact vision recovery: vascular system alterations and stress hormone influence thereon, brain mechanisms of neuroplasticity, cerebrospinal fluid (CSF) pressure, emotional stress etc. Though indirect, they are by no means less relevant for our understanding of low vision and its treatment to achieve recovery and repair.

\section{Neurological influences in "ocular" diseases}

Partial vision loss, with sometimes considerable "residual vision" (Fig. 1) is by far more prevalent (>95\%) than total vision loss. When vision loss develops in ocular diseases affecting the retina and optic nerve, this has repercussions at the level of brain processing as well. Though it is textbook knowledge that the retina is part of the brain, the complexity of the interaction between eye and brain is seldom considered and not such a simple matter. Here we need to ask on the one hand (i) how much neuronal information reaches the brain, and on the other hand we also should learn (ii) how the brain processes incoming (incomplete) visual information by ignoring, enhancing (amplifying) or inhibiting (suppressing) it, and (iii) how visual cues are interpreted by emotions and cognition and how this impacts overall vision. On a systems level, the brain, by releasing stress hormones influence vascular tone, particularly in and around the optic nerve and thereby impair vascular autoregulation and perfusion of the whole body, including itself and that of the eyes (Flammer et al., 2013a). Furthermore, the brain is involved in other ways in eye pathology a partner in the intraocular (IOP)/ intracranial pressure (ICP) balance which directly or indirectly impacts the consequences of eye pressure conditions (Hou et al., 2016). If any of these 


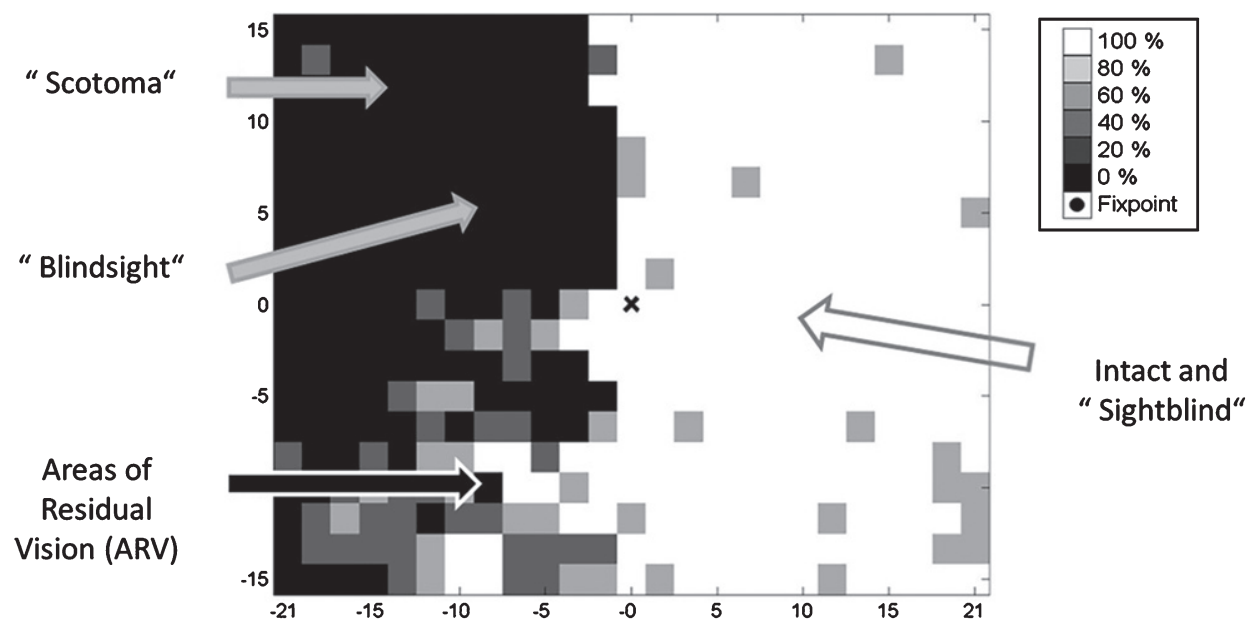

Fig. 1. Residual functions and subtle deficits in visual fields. Visual fields are not just black and white (blind and seeing fields) have "shades of grey": hidden potentials with residual vision but also hidden problems in the "intact" sector. Blindsight is the phenomenon that patients are able to correctly guess that stimuli were presented without being aware of them. While correctly responding to vision signals, they report seeing nothing; unconscious seeing without knowing. Areas of residual vision are those with uncertain responses where patients respond only occasionally. These regions of the visual field are quite variable during repeated testing and are characterized by increased thresholds and longer response time. The hidden deficits in the "seeing field" make patients "sightblind", but this can only be measured by tests that are sensitive to higher cognitive dysfunctions.

brain regulation mechanisms are altered, the braineye-vascular triad has a sensitive balancing act to manage which determines if, how, and when a vision problem is first diagnosed, whether it progresses, or whether it can be activated for recovery and restoration.

\subsection{Residual vision}

A neurobiological substrate that supports visual field recovery and restoration are regions of partial visual functions, termed "areas of residual vision" (Sabel, Fedorov, Henrich-Noack \& Gall, 2011a). These are regions in the visual field which are neither blind nor seeing normally (graphically displayed in visual field charts in black or white color, respectively). Rather, visual fields typically have different "shades of grey" where function is neither completely lost nor normal (see Fig. 1). Most patients have some residual structures and functions spared by the damage; complete vision loss in both eyes ("blackblind") is extremely rare. Residual (partial) vision - where vision is not lost but impaired - can easily be subjectively reported by patients and quantified with perimetry testing. They are measurable as a "relative scotoma" inside or at the border of the scotoma. Such residual areas are characterized by higher response thresholds, lower contrast sensitivity, reduced acuity, foggy vision, incomplete perceptions or slowed reaction times (Bola et al., 2013). It is these partially damaged regions of residual vision that have hidden potentials for activation and recovery.

The phenomenon of "blindsight" is an interesting and long-known example of residual vision: blindsight patients are able to correctly guess that stimuli were presented without being aware of them. While they correctly respond to vision signals, the patients report seeing nothing ("blind"); it is a case of unconscious seeing without knowing (Pöppel, Held \& Frost, 1973; Sanders, Warrington, Marshall \& Weiskrantz, 1974). Other areas of residual vision are those with uncertain or less sensitive responses which are shown in grey in visual field charts. Here patients respond only sometimes to stimuli. The response is quite variable during repeated testing (Flammer, Drance \& Fankhauser, 1984a; Flammer, Drance \& Schulzer, 1984b) and characterized by increased thresholds and longer response times. But visual fields may also have hidden deficits inside the presumably "intact" areas which cannot be captured by standard perimetric testing. Such patients are ,sightblind" (Bola, Gall \& Sabel, 2013). However, we do not propose a clear-cut border between "blindsight" and "residual vision". Both may represent different levels of visual system activation supporting different levels of awareness to be analysed on a network level (Hadid \& Lepore 2017; Mazzi, Savazzi \& Silvanto, 2018), an issue that needs to be further explored. 


\subsection{Brain degeneration in ocular disease}

Nervous system degeneration in (normal) aging can affect the structure and function anywhere along the visual eye-to-brain axis (Haas, Flammer \& Schneider, 1986). Obviously, what the brain perceives is a function of how much retinal input it receives. But if the brain is also affected by any additional loss of neurons, loss of functional connections in down-stream visual structures, or vascular autoregulation problems, then the complexity of the "eye problem" is far greater (Faiq, Dada, Kumar, Saluja \& Dada, 2016). This is the case when, for example, general cell loss occurs during normal aging with specific vulnerabilities of the brain's visual system structures (Owsley, 2011). Even in traditionally ocular diseases (such as glaucoma), a selective degeneration of cells in visual brain nuclei has been shown as indicated by atrophy of the LGN, optic radiation and visual cortex (Duncan, Sumple, Weinreb, Bowd \& Zangwill, 2007; Gupta, Ang, de Tilly, Bidaisee \& Yucel, 2006; Gupta \& Yucel, 2007; Engelhorn et al., 2011; Yücel, 2013; Yu et al., 2013, Schoemann et al., 2014), and even non-visual brain structures that control emotions (e.g. amygdala) (Wang et al., 2016).

\subsection{The brain-eye-vascular triad}

Not only the eye-brain interaction but also their respective coaction with the cardiovascular system influences vision loss (Fig. 2) (Flammer et al., 2013a). For example, glaucomatous optic neuropathy (GON) was long considered to be a mechanical insult imposed by elevated intraocular pressure (IOP) on the optic nerve head $(\mathrm{ONH})$ resulting in $\mathrm{ONH}$ excavation and - secondarily - degeneration of the inner layer of the retina and of the optic nerve head. But this explanation is too simple for the following reasons: (i) GON involves the entire optic pathway including different brain structures to an extent larger than trans-synaptic degeneration would explain, (ii) GON can develop at either an elevated or a normal level of IOP, and (iii) occular blood flow (OBF) reduction is not confined to the eye but also happens in other body parts such as in nail fold capillaries and the brain, and this precedes the damage (Flammer et al., 2002).

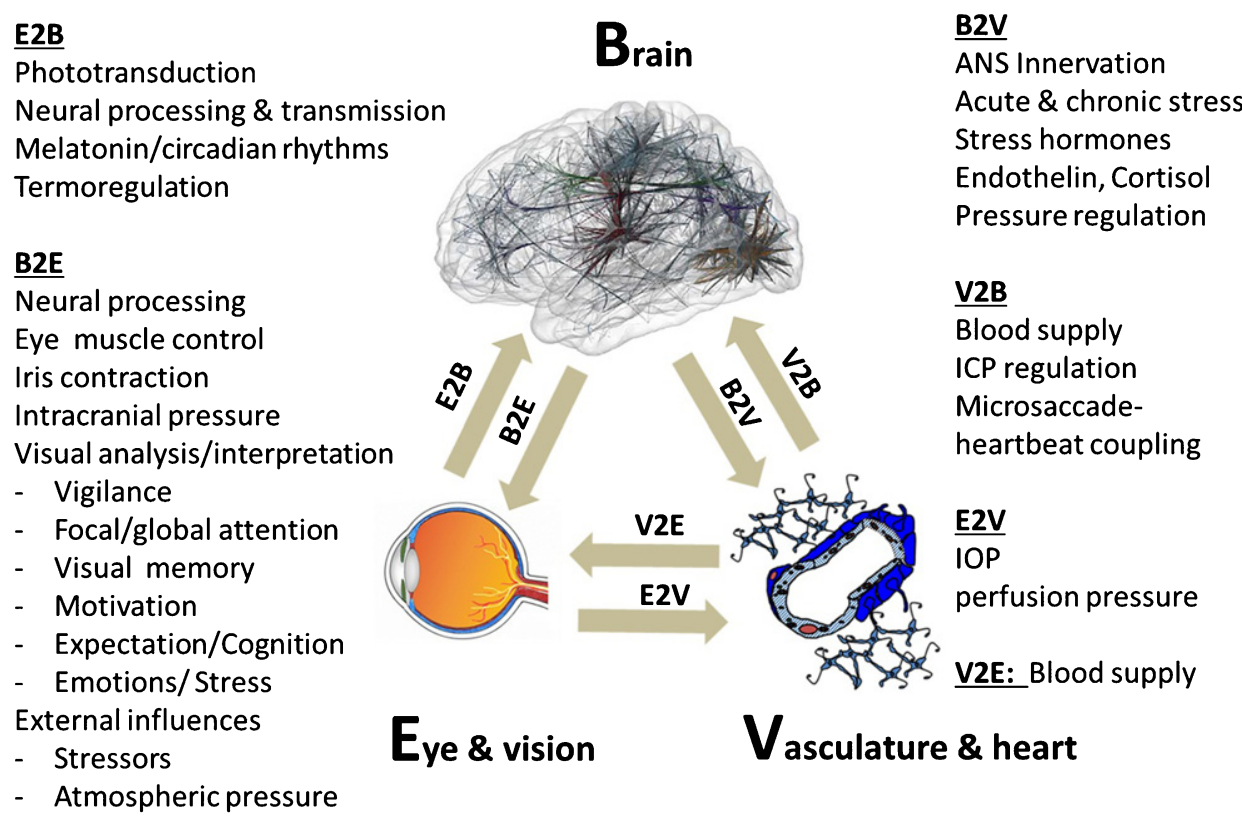

Fig. 2. The brain-eye-vascular triad. This triad illustrates the interdependency of the three organ systems and their role in vision loss. The retina, which transforms light rays to electrical cell signals weighs only about 1 gram. But the estimated weight of the brain areas needed to support normal vision is on the order of several hundred grams. To understand the causes and consequences of vision loss, and to find new treatment options, the eye and the visual system cannot be viewed in isolation but rather need to be considered within the holistic context of different systems throughout the brain and vascular system. The arrows indicate the direction of interaction between brain (b), vascular system (v) and eye (e). The eye-brain influence is denoted as E2B (eye-to-brain) and B2E (brain-to-eye or brain-to-central visual structures). Such interactions can be direct or indirect. Note: blood flow is not only important for delivering nutrition / oxygen and removal of metabolic by-products, but it is also important for thermo-regulation when the eye is exposed to extreme heat or cold. IOP is at least in part regulated by the brain. 


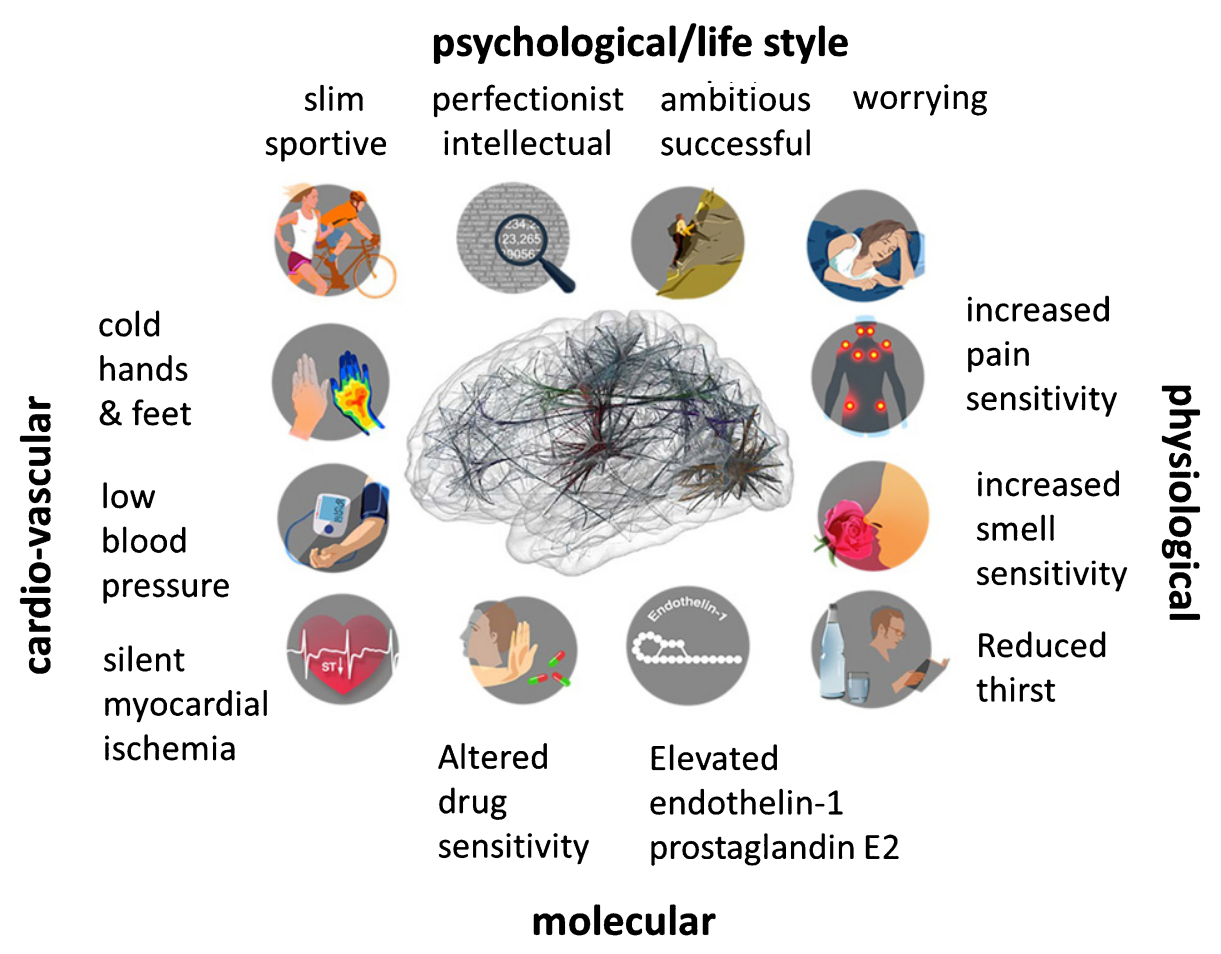

Fig. 3. Emotional stress and the "Flammer Syndrome". The term Flammer Syndrome (FS) describes a phenotype characterized by the presence of primary vascular dysregulation with a cluster of additional symptoms and signs. Symptoms and signs include the following: prolonged sleep onset time, prolonged blood flow cessation in the finger capillaries after cooling, disturbed autoregulation of ocular blood flow, increased prevalence of optic disc hemorrhages and activated retinal astrocytes, increased retinal venous pressure, increased stiffness of retinal vessels, higher spatial irregularities in retinal vessels, increased resistance in retroocular vessels, increased oxidative stress, altered gene expression as measured in lymphocytes, and altered activity of the autonomic nervous system (beat-to-beat variations of the heart).

The response to vascular challenges varies among individuals. It is influenced by environmental factors and genetic predispositions as exemplified by the Flammer Syndrome (FS). Such persons have a tendency to react differently (particularly with their blood vessels) to a number of stimuli such as coldness or emotional stress (Konieczka et al., 2014). Hence, we need to appreciate the important role of the brain-vascular interaction in vision loss.

Embryologically, the eye develops from brain tissue, and both blood flow (blood brain barrier) and cell types (neurons) are similar. But retinal vessels lack innervation by the autonomic nervous system (ANS) and the blood brain barrier is incomplete in the optic nerve head, rendering it more sensitive to circulating vasoactive molecules such as Endothelin-1. The term Flammer Syndrome describes a phenotype characterized by the presence of primary vascular dysregulation with a cluster of additional symptoms and signs. FS is protective against certain diseases such as arteriosclerosis but contributes to other diseases such as normal tension glaucoma (Konieczka \& Erb, 2017).
FS occurs more often in females than in males, in slender people then in obese subjects, in people with indoor rather than outdoor jobs, and in academics than in labourers (Mozaffarieh et al., 2010). Individuals with FS are characterized by additional signs and symptoms which include the following: prolonged sleep onset time (Pache et al., 2001), prolonged blood flow cessation in the finger capillaries after cooling (Mahler, Saner, Würbel \& Flammer, 1989), disturbed autoregulation of ocular blood flow (Gherghel et al., 1999), increased prevalence of optic disc haemorrhage (Grieshaber, Terhorst \& Flammer, 2006) and activated retinal astrocytes, increased retinal venous pressure (Fang, Baertschi \& Mozzaffarieh, 2014), increased stiffness of retinal vessels, higher spatial irregularities in retinal vessels (Kochkorov et al., 2006), increased resistance in retroocular vessels (Gherghel et al., 1999), increased oxidative stress (Mozaffarieh et al., 2008), altered gene expression as measured in the lymphocytes (Yeghiazaryan, Flammer, Orgül, Wunderlich \& Golubnitschaja, 2009) and altered activity of the ANS (beat-to-beat variation of the heart) (Flammer \& Konieczka, 2017). 
Individuals with FS also have generally increased sensitivities to high altitudes (Baertschi, DayhawBarker \& Flammer, 2016) and changes in weather conditions (atmospheric pressure), vibration, as well as pain sensation and muscle cramps. There are also typical psychological characteristics as individuals tend to be worrisome, remarkably assiduous and perfectionists (Konieczka \& Flammer, 2016).

Figure 3 illustrates the most characteristic symptoms and signs. Its clinical relevance lies in its association with eye diseases (Flammer, Pache \& Resink, 2001) such as normal tension glaucoma, retinitis pigmentosa (Konieczka, Koch, Schoetzau \& Todorova, 2016a), increased retinal venous pressure (Fang et al., 2014), retinal vein occlusion (Flammer \& Konieczka, 2015), brain diseases such as multiple sclerosis (Konieczka, Koch, Binggeli, Schoetzau \& Kesselring, 2016b), optic nerve compartment syndrome (Flammer, Konieczka \& Flammer, 2013b), preoperative ischemic optic neuropathy (Bojinova, Konieczka, Meyer \& Todorova, 2016), and inner ear diseases such as tinnitus or sudden hearing loss (Flammer et al., 2013b).

Of note, while the FS affects many patients that suffer vision loss, the relationship between FS and vision loss is one of association, not necessarily one of causality. This requires further study, but current evidence suggests that excessive mental stress may be one of the main underlying cause of both (Sabel, Wang, Cárdenas-Morales, Faiq \& Heim, 2018).

\subsection{Emotions, mental stress and vision impairment}

Many of the FS signs are quite typical also for the response to emotional stress which suggests that mental stress may not only be the consequence but also the cause of VI (Sabel et al., 2018). In fact, in clinical practice many patients report that their vision loss occurred at the time of heightened or prolonged mental stress and anxiety. Hence, how stress affects the eye, optic nerve, and brain is an issue that should not to be ignored. On the one hand, the changes of beat-to-beat variations of the heart indicate an involvement of the autonomic nervous system (Kurysheva, Ryabova \& Shlapak, 2018) and explain the response of the densely innervated retroocular vessels and the choroid to stress. On the other hand, vessels in and around the optic nerve become constricted by vasoconstrictors such as angiotensin II, endothelin, or adrenalin which reduce blood flow during emotional excitement (Sossi \& Anderson, 1983).
Indeed, FS patients have higher levels of the stress hormone endothelin (Flammer \& Konieczka, 2015) and may suffer from AION under stress (Flammer et al., 2013b). The following accounts are anecdotal and meant to illustrate how acute stress can influence blood flow and vision loss. One of the authors (J.F.) saw three bankers who developed AION when the share-values on the stock market suddenly dropped and observed a 12 year old girl with AION after major school related stress. Another case was an opera singer who was examined with capillary-microscopy after exposing the latter patient to cold provocation which made the blood flow stop for $20 \mathrm{sec}$. When she later revealed her marital problems, blood flow stopped again for three minutes. That glaucoma is associated with psychosomatic components is supported by the observation that women showing FS signs (e.g. cold extremities, prolonged sleep onset latency) have a tendency to suppress anger because of stereotypic feminine gender socialization (van Arb et al., 2009), and normal-tension glaucoma patients show significantly more complaints and emotional instability (Erb et al., 1999).

Another frequent observation in the clinical context is that patients report their subjective impression that stress influences vision loss as they noticed the coincidence of a history of excessive mental stress and the time of their vision loss and worsening of the visual field during or after acute stress.

Thus, the striking resemblance of FS and psychological adaptation problems in response to emotional stressors suggests that VI may have an important, yet little appreciated, psychosomatic component. Stress is known to trigger autonomic respiratory and cardiovascular changes, and - from an evolutionary perspective - stress is adaptive to prepare for the "fight-or-flight" response. But long-lasting psychological stress unfavorably impacts the vascular system in the eye and brain as shown in both lab animals and humans. For example, acute or chronic stress can alter motor and sensory performance in laboratory rats (Metz, Schwab \& Welzl, 2001), and cold hands in humans are one of the bodily reactions to mental stress (e.g. during job interviews, oral exams, or stage anxiety).

The reactivity to stressors is controlled by the brain, where the dorsomedial hypothalamus (DMH) (Dampney, 2015) translates mental (psychological) states to a biological (medical) response. DMH receives neuronal input from emotional circuits of the cortex, amygdala, and other forebrain structures and mediates the cognitive and emotional appraisal by the 
brain, triggering a cascade of autonomic, respiratory, vascular and neuroendocrine responses. And there are phylogenetically ancient midbrain structures controlling the reflexive survival systems when exposed to sudden and threatening stimuli: the periaqueductal gray, the colliculi, and the basal ganglia that control the orienting and the cardiorespiratory responses. Known bodily reactions to stress include vessel contraction in the skin, skeletal muscles tension, and various visceral reactions. Blood vessel spasms can cause not only visual problems (Flammer et al., 2001) but also sudden hearing loss, vertigo or stroke.

Thus, emotional stress may trigger the manifestation of vascular dysregulation in the eye and/or brain with subsequent increase of oxidative stress or may even lead to cell death (Shily, 1987). Clearly, there is a psychosomatic component to VI because the stress response has a remarkable, though indirect, influence on eye and brain vasculature. This, in turn, contributes to - or maybe even be the major causes of - vision loss (Sabel et al., 2018), especially in AION or glaucoma (Flammer et al., 2013b). The remedy is to manage mental stress by relaxation exercises such as meditation and yoga which can reduce anxiety, normalize IOP, and improve blood flow (Backon et al., 1990; Shemagonov \& Sidorenko, 2000; Chen et al., 2012; Tang, Holzel \& Posner, 2015; Dada et al., 2018).

Clearly, at this point the relationship between psychological factors, vascular factors and ocular impairments is still vague. Stress has been proposed to be both a consequence and major (though by no means unique) cause of vision loss (for further details, see Sabel et al., 2018). The role of stress in the etiology of various eye diseases requires further study with the proof of causality still to be explored further (Dada et al., 2018).

\subsection{Intracranial pressure in eye diseases}

Another proposed brain contribution to retina and optic nerve health is intracranial pressure (ICP), though this is still a matter of debate. According to recent proposals, the cerebrospinal fluid (CSF) exchange in the optic nerve subarachnoid space (ONSAS) is a kind of "communicating" channel between the cerebral and the ocular pressure compartments. When ICP drops, so does the ON-SAS pressure. However, when lowering ICP by CSF shunting in normal dogs below a critical threshold, the pressure decline in the optic nerve chamber stops, indicating CSF flow arrest where CSF can no longer flow freely from the brain cavity into the optic nerve chamber
(Hou et al., 2016). Nutrients are no longer delivered, and metabolic products excreted by the cells are no longer flushed out, leading to an unhealthy biochemical ecosystem much like a "dead pond" lacking fresh water inflow (Hou et al., 2016). Thus, the traditional view that the IOP rise is the sole cause of damage to the optic nerve head in glaucoma is too limited, unless the ICP and perfusion of the eye are also considered. This is especially true for normal tension glaucoma (Berdahl, Allingham \& Johnson, 2008). Indeed, acute ICP reduction damages RGC axons (Zhang, Kedar, Lynn, Newman \& Biousse, 2006) and when lowering ICP by CSF shunting in monkeys over the course of one year the optic nerve is damaged (Yang et al., 2014). The IOP/ICP balance is therefore another example how major "ocular diseases" may also be "brain diseases" in disguise. In patients with an optic nerve compartment syndrome (Killer et al., 2007), a particularly frequent condition in subjects with FS (Flammer et al., 2013b), there is a proven segregation of CSF between the ON-SAS and the intracranial subarachnoid space. This leads to measurable differences in fluid composition and pressure and this is often reversible if FS is treated (Konieczka et al., 2016c).

But how is brain pressure regulated? Interestingly, neurons in the dorsomedial hypothalamus (DMH) (Samuels et al., 2012), the structure mediating the stress response and the surrounding perifornical area (mentioned above) influence both the ICP and IOP. Thus, it is the brain that regulates the balance between IOP and ICP, but when the neural activity in the $\mathrm{DMH} / \mathrm{PeF}$ is impaired or stimulated, the ICP and IOP may be uncoupled and regulated independently (Hou et al., 2016).

\subsection{Brain and eye movement control}

Voluntary and involuntary eye and head movements mostly visit objects that are relevant to the action and gaze control. This requires the precise coordination of different muscles of the eyes and/or head and trunk which are tightly tuned by midbrain and frontal (cortical) regions to ascertain both flexibility of movement and stability of gaze and assist the planning, coordination and execution of behavioural responses (Land 2006; Proudlock \& Gottlob, 2007). If eye movements or eye-head coordination are impaired, this could be an important source of vision problems in strabismus, double vision, fixation problems, saccadic behavior, and nystagmus. Especially microsaccades are altered in classic "eye" diseases such as glaucoma (Kanjee, Yücel, Steinbach, 
González \& Gupta, 2012; Faiq et al., 2016) and amblyopia (Shi et al., 2012). Also in different dementias microsaccadic eye movements are of interest as they may have clinical utility in early detection (MacAskill \& Anderson, 2016). For example, microsaccades (MS), small, fast, jerk-like eye movements that happen once or twice per second (Martinez-Conde, Otero-Millan \& Macknik, 2013) serve the function of counteracting foveal and peripheral fading, which is critical for high-acuity vision (Winterson \& Collewijn, 1976). In fact, one of the authors (B.S.) recently uncovered that microsaccades are critical for "cortical refreshment" of visual processing, a mechanism, if disturbed, is expected to directly impact visual functions (Gao, Huber \& Sabel, 2018). While the role of larger saccades in eye diseases has been studied extensively, the role of microsaccades in ophthalmological and neurological problems is only now being explored. In a recent study by Gao and Sabel (2017) hemianopic stroke patients showed microsaccade enlargement and impaired binocular conjugacy. This was interpreted to indicate that malfunctioning microsaccadic control circuits worsen over time and an apparent microsaccade bias towards the seeing field was suggestive of greater allocation of attention to accelerate stimulus detection as the brain may try to compensate the vision impairment. Interestingly, besides counteracting fading (i.e. refreshment of the retinal photoreceptors firing) microsaccades may also play a role in controlling brain physiological activity by resetting oscillations in the alpha frequency band (Gao et al., 2018). Of note, microsaccades interact with the vascular system because they are coupled to the heartbeat (Ohl, Wohltat, Kliegl, Pollatos \& Engbert, 2016).

\subsection{Top-down control of residual vision}

Whatever the cause of vision loss may be, the key question is how the brain can best handle residual visual signals when the damage is already done. According to the "residual vision activation theory" (Sabel et al., 2011b) residual (partially damaged) structures, for example in optic neuropathy, are disadvantaged in several ways: (i) partially damaged regions have fewer neurons which reduces physiological summation post-synaptically, (ii) their dysfunctional state comprises a perceptual "distraction" so that the brain preferentially allocates attentional resources to intact visual field sectors to reduce ambiguity, and (iii) their temporal processing is impaired due to desynchronized brain networks. In addition, there is remote damage beyond the injured region, and this magnifies the problem: (i) even presumably "intact" visual field sector have subtle perceptual impairments ("sightblind") (Bola et al., 2013) and (ii) long-range functional connectivity networks are disturbed as shown by EEG recordings (Bola, Gall \& Sabel, 2015). This is compatible with reports of distant activation changes after local lesions as shown with functional magnetic resonance imaging (fMRI) (Marshall et al., 2008). Thus, not only "bottom-up" (retinofugal) but also "top-down" (cognitive/attention) brain mechanisms are part of the problem in vision loss of "eye" diseases.

One important "top-down" mechanism that modulates visual perception is attention. The brain has a natural tendency to direct its attention toward the intact visual field sector, "ignoring" the damaged sectors of the visual field to reduce ambiguity. This leads to "non-use" of residual structures near the scotoma which reduces their neuronal activity and synaptic transmission. But that such "neglected" residual structures can - in principle - be reactivated is suggested by the following observations: (i) lifting pressure from the optic nerve in Graves' orbitopathy (Gasser \& Flammer, 1986) or from the chiasm following removal of a pituitary adenoma leads to rapid recovery of vision (Gnanalingham, Bhattacharjee, Pennington, Ng, Mendoza, 2005), (ii) focusing attention onto areas of residual vision (relative scotomas) in hemianopia instantaneously improves visual detection in the attended visual field sector (Poggel, Kasten, Müller-Oehring, Bunzenthal \& Sabel, 2006a), (iii) daily attention training improves vision permanently (Poggel, Kasten \& Sabel, 2004), and (iv) hemianopia patients with faster visual processing (reduced reaction time) in areas of residual vision show a microsaccade direction bias towards the intact hemifield (Gao et al., 2018).

Besides attention, there are other "top-down" brain modulating mechanisms of residual vision such as fatigue, acute anxiety, expectation, and cross modal (auditory) co-activation. Yet another sign of "topdown" influences are pseudo-hallucinations (such as the Charles-Bonnet-Syndrome) in patients with vision loss (Kölmel, 1986; Schultz \& Melzack, 1991), especially at the time when their vision recovers (Poggel et al., 2006b; Tan, Sabel \& Goh, 2006).

Clearly, vision loss is not just a function of how many cells survive (e.g. after optic nerve damage), but if and how well the top-down brain network processes any residual input surviving the damage. To use an 
analogy: whether we hear music from the stage is not just a matter of the microphone but also one of the amplifier.

\section{Visual problems in neurological diseases}

Visual and eye movement dysfunctions are also frequent problems in different neurological diseases because many brain regions are critical for visually guided performance. While a complete discussion of this field is beyond the scope of this review, some examples are mentioned here where non-visual diseases have visual system involvement. In traumatic brain injury and stroke, for example, a variety of visual diseases result in diplopia (i.e. double vision due to ocular misalignment), visual field size reductions (i.e. hemianopia) or different perceptual and attention related disturbances. But also "nonvisual" neurodegenerative diseases impact visual function. For example, the progressive CNS demyelination in multiple sclerosis (MS) is often associated with vision (Meienberg, Flammer \& Ludin, 1982; Costello, 2016), motor and cognitive impairments. Here, optic neuritis, an early MS symptom, leads to reduced visual acuity, sensitivity to contrast, impaired colour discrimination, and central visual field loss on the one hand and oculomotor deficits (e.g. internuclear ophthalmoplegia) with double vision on the other hand. Another example is Parkinson's disease (PD), a movement disorder caused by degeneration of the extrapyramidal motor system's dopaminergic neurons, which also manifests deficits in visual acuity, contrast sensitivity, colour discrimination, eye movement, visuospatial and motion perception and visual processing speed (Bodis-Wollner, 1990; Armstrong \& Kergoat, 2015). Even dementias, such as Alzheimer's disease (AD), can cause visual impairments, particularly in the elderly (Armstrong \& Kergoat, 2015). Here, abnormal $\beta$-amyloid protein depositions in the brain leads not only to the wellknown cognitive deficits but also to a variety of visual impairments including decreased visual acuity, colour vision and visual fields, or impairments in eye fixation and smooth and saccadic eye movements (Armstrong \& Syed, 1996).

As with other degenerative conditions, pathological changes have been observed at the level of the eye, subcortical visual pathways as well as visual cortical processing areas. Interestingly, Wostyn, Audenaert \& De Deyn (2010) argue that $\mathrm{AD}$ also shares certain features with glaucoma in that both conditions lead to RGC death. Other neuropsychiatric disorders with visual system disturbance are psychosis/schizophrenia, autism, and dyslexia (Pammer, 2014; Stein, 2014; Williams, Fink, Zamora \& Borchert, 2014; Silverstein \& Rosen, 2015; Morris et al., 2015). Finally, neurodevelopmental condition such as cerebral palsy and Down's Syndrome also manifest characteristic visual disturbances. A study of 120 children with cerebral palsy found that $50 \%$ had strabismus and/or significant refractive error and $11 \%$ had visual field defects (Black, 1982). Crucially, children with cerebral palsy are often affected by unique visual/behavioural dysfunctions, e.g. visuospatial and motion processing, complexity/crowding, and attention deficits (Armstrong, 2011).

\section{Brain reorganization, vision recovery and restoration}

The numerous cases of overlap between eye and brain problems suggests that neuroscience may hold the key for major progress the field of vision loss and help propel clinical care beyond eye drops or surgery. It is through the modulation of top-down influences of higher-up brain regions that the brain can help to amplify residual vision by neuronal network plasticity and reorganization. The brain has a now widely recognized ability to modify its structure and function, even in adulthood (Freund, Sabel \& Witte, 1997; Pascual-Leone, Amedi, Fregni \& Merabet, 2005). Yet, much effort is made to also improve vision loss by experimentally repairing the damaged structure itself by way of neuronal regeneration or stem cell implantation.

\subsection{Regeneration, stem cells, and retinal implants}

Protecting, replacing or regenerating cells to restore vision is currently a very active research field. However, adequately summarizing this basic research field is beyond the scope of this review and readers should refer to other sources (Fernandes, Diniz, Ribeiro \& Humayun, 2012; Shepherd, Shivdasani, Nayagam, Williams \& Blamey, 2013; Lewis \& Rosenfeld, 2016; Rachitskaya \& Yan, 2016; Bosking, Beauchamp \& Yoshor, 2017; Cheng, Greenberg \& Borton, 2017; Chun \& Cestari, 2017; Benowitz, He \& Goldberg, 2017; Calkins, Pekny, Cooper \& Benowitz, 2017; Pardue \& Allen 2018; Najarpour Foroushani, Pack \& Sawan, 2018). Briefly, clinical 
trials on axonal regeneration, though promising experimentally, have not been carried out due to the still too limited regeneration potential (de Lima, Habboub \& Benowitz, 2012). Other approaches include the cell replacement and visual restoration by retinal tissue sheets aimed at increasing visual responsiveness to light by establishing synaptic connections between the transplant and the host (Seiler \& Aramant, 2012). But stem cell transplantation was only tried in few patients and is not ready for wide scale clinical application (Whiting, Kerby, Coffey, da Cruz \& McKernan, 2015).

Other attempts to improve or augment the damaged part of the visual system are prosthetic devices using either electrode arrays or electronic chips aimed at stimulating neuronal tissue. The first implants were used to stimulate visual cortex directly (see Fernandes et al., 2012; Lewis \& Rosenfeld, 2016 for reviews). Here, focal electrical stimulation were delivered to create sensations of discrete points of light (called "phosphenes") that are supposed to mimic pixels of vision. An image captured by camera or chip defined multi-site patterns of electrical stimulation with the aim to mirror the geometrical pattern of the visual world into neurophysiological impulses to create the perception of shapes, images, or objects, such as letters. However, technical and surgical complications of brain electrode implants (risks of invasive surgery, neural coding problems, etc.; Merabet, 2011; Hadjinicolaou, Meffin, Maturana, Cloherty \& Ibbotson, 2015) have hampered early efforts. But new technological advancements such as electrode design and image processing have generated renewed interest in this approach (Bosking et al., 2017; Najarpour Foroushani et al., 2018) and clinical trials are in progress (https://clinicaltrials.gov/ ct2/show/NCT03344848).

Alternatively, miniature prosthetic devices have been implanted in the eye to stimulate the retina with the aim to improve vision. This has been studied in retinal pathologies such as retinitis pigmentosa (RP) and age-related macular degeneration (ARMD) (Merabet, 2011; Mills, Jalil \& Stanga, 2017). Briefly, the fundamental idea is to substitute damaged photoreceptor function by stimulating retinal ganglion cells directly. Early clinical tests of the Argus II Retinal Prosthesis Study and others have been encouraging and show, at least in principle, that patterned electrical stimulation can evoke patterned light perceptions (Rachitskaya \& Yuan, 2016; Cheng et al., 2017). However, if and to what extent the artificial visual impulses are meaningfully processed by the brain to create useful functional vision and improve quality of life needs further study (Merabet, Rizzo, Amedi, Somers \& Pascual-Leone, 2005, 2007; Shepherd et al., 2013). Other remaining issues include the risk of neurodegeneration due to long surgical sessions, the effect of chronic electrical stimulation, and the concern if completely blind patients really benefit from artificial vision given that they have learned to compensate by using their other senses.

\subsection{Cross-modal plasticity}

Individuals living with blindness have to make dramatic behavioral and compensatory adjustments in order to remain functionally independent in a world that relies heavily on vision (Merabet \& PascualLeone, 2010). In cases of congenital or early onset blindness patients rely more on non-visual senses such as hearing and touch which is associated with dramatic neuroplastic changes in brain structure and function (Bauer et al., 2017). In particular, regions of the brain normally ascribed to visual processing are co-opted to process tactile and auditory information. There is also evidence that blind individuals may show greater performance on higher order cognitive functions such as language and memory and, in some cases, outperform normally sighted peers (Merabet $\&$ Pascual-Leone, 2010). This functional recruitment of occipital cortex for non-visual processing is referred to as "cross-modal plasticity". For example, neuroimaging studies revealed that blind individuals show robust activation in occipital cortical areas while performing a variety of nonvisual tasks such as Braille reading (Sadato et al., 1996), sound localization (Gougoux, Zatorre, Lassonde, Voss \& Lepore, 2005), odor perception (Kupers et al., 2011), or higher order cognitive tasks such as language processing (Röder, Stock, Bien, Neville \& Rösler, 2002; Bedny, Pascual-Leone, Dodell-Feder, Fedorenko \& Saxe, 2011) and verbal memory recall (Amedi, Floel, Zohary \& Cohen, 2003).

Evidence for the functional significance of occipital cortex recruitment arises from both clinical and experimental studies. For example, a congenitally blind, highly proficient Braille reader was rendered alexic for Braille reading following bilateral occipital cortex stroke (Hamilton, Keenan, Catala $\&$ Pascual-Leone, 2000). Experimental studies of transcranial magnetic stimulation (TMS) pulses can non-invasively and reversibly disrupt localized cortical activity when delivered to occipital cortical areas 
of the blind that carry out Braille reading (Cohen et al., 1997), auditory localization (Collignon et al., 2011) or language processing (Amedi et al., 2004). But the importance of this cross modal recruitment in terms of impacting the value of sight restoration efforts (e.g. retinal prostheses) or residual function activation in the partially blind remains largely unknown and deserves more careful consideration. Thus, the study of cross modal plasticity may provide insight towards the development of post-implantation rehabilitative strategies and can be used to optimize behavioral outcomes (Merabet et al., 2005; Merabet \& Pascual-Leone, 2010). However, we need to be aware that some instances of plasticity may be maladaptive which is of concern for visual rehabilitation (Merabet \& Pascual-Leone, 2010).

\subsection{Reactivation of silenced cells}

It seems a straight forward thought that after damage there are not only healthy and dying but also "silent" neurons. These silent neurons can be considered too healthy to die, but too sick to function normally. Activating these "silent" neurons could maximize potential for recovery. How could this be explained? When stimulation of neurons, i.e. by flickering light onto the retina, the neurons need to fire vigorously which requires additional glucose and oxygen. If this stimulation is not accompanied by appropriate upstream blood vessel dilation (because neurovascular coupling is impaired by vascular dysregulation(VD)), the neurons get "locked-in" a hypometabolic "resting" state and cannot rapidly fire action potentials and remain "silent". As discussed above, VD is found in many diseases and the question needs to be studied if, or to what extent, VD is ratelimiting for neuronal activation of "silenced" neurons and if this hypo-metabolic state can be reversed as a possible source of activating visual reserve.

The evidence for the existence of dormant (silent) neurons or neural networks is still rather indirect: (i) there is often a surprising degree of natural recovery in the early phase after the lesion (Sabel, 1999; Zhang et al., 2006) which cannot be explained by edema resolution or axon regeneration, (ii) residual vision can be improved by vision training, drugs or noninvasive brain current stimulation (discussed below), and (iii) functional connectivity networks of the brain can reorganize after damage (Gilbert \& Wiesel, 1992; Bola et al., 2014) (see Table 1). This proposal of a hypometabolic state was already implied by experimental finding in glaucomatous monkeys that showed that optic atrophy is associated with a non-selective reduction of metabolism of neurons in afferent visual structures (Harwerth et al, 2002). Clearly, the concept of reactivating hypo-metabolic neurons as a basis for recovery has a certain charm because reactivated neurons have been involved in visual processing before and thus are pretuned to respond to visual stimuli.

\subsection{Perceptual learning and vision training}

The neurobiological basis of normal learning and memory formation is the strengthening of synaptic connections through repetitive activation of neuronal assemblies (Cotman \& Berchtold, 2002). When neurons repeatedly fire action potentials, this will cause the release of neurotrophic factors from the postsynaptic membrane which stimulates pre-synaptic synapse formation and facilitates neurotransmission. But because learning and plasticity of vision is not restricted to early childhood but extends into adulthood and old age, perceptual learning - a change in performance following training - can improve performance in detection threshold tasks (Marra \& Flammer, 1991), gratings, hyperacuity, motion, or texture to super-normal levels (Fahle, 2002). For example, Michelson asked normal volunteers to train their vision with ten $30 \mathrm{~min}$ sessions for vision acuity and contrast sensitivity and this increased performance by $32 \%$ and $47 \%$, respectively (Otto $\&$ Michelson, 2014). Likewise, vision training can strengthen residual vision in patients with visual system damage, no matter what caused the vision loss such as posterior stroke optic nerve damage (Kasten, Wüst, Behrens-Baumann \& Sabel, 1998), glaucoma (Sabel \& Gudlin, 2014), amblyopia (Polat, Ma-Naim, Belkin \& Sagi, 2004), and macular degeneration (reviewed in Sabel et al., 2011a; Anastassiou, Schneegans, Selbach \& Kremmer, 2013). In hemianopia, vision restoration training of the scotoma border (Kasten et al., 1998; Romano, Schulz \& Kenkel, 2008) or deep inside the blind field (Sahraie et al., 2006; Jobke, Kasten \& Sabel, 2009) and can significantly improve performance which is accompanied by increased oxygenation (Marshall et al., 2008). Visual training stimuli typically include near- or super-threshold detection tasks (perimetry), visual acuity, contrast sensitivity, movement detection (Huxlin et al., 2009), or reading (Sabel et al., 2011a); in other paradigms multisensory (auditory) cues were used as well (Bolognini, Rasi, Coccia \& Ládavas, 2005). However, some studies did not find evidence that vision training improves visual field 
Table 1

Selected publications on methods to improve visual fields in low vision following either vision training (behavioral exercises), non-invasive brain current stimulation, or drug treatment (see reviews by Sabel et al. 2011b; Matteo et al. 2016; de Haan et al. 2014 and further studies in the reference list)

\begin{tabular}{|c|c|c|c|}
\hline Reference & Indication & Treatment / study design & Improvements \\
\hline \multicolumn{4}{|l|}{ Vision Training } \\
\hline Polat (2004) & Amblyopia & $\begin{array}{l}\text { Training with Gabor patterns }(n=77) \\
\text { vs. control }(n=16), \text { RCS }\end{array}$ & contrast sensitivity, acuity \\
\hline Sabel (2014) & Glaucoma & $\begin{array}{l}\text { VRT }(n=15) \text { vs. visual } \\
\text { discrimination training }(n=15) 6 \\
\text { x/week, } 2 x \text { daily for } 30 \mathrm{~min}, \mathrm{RCS}\end{array}$ & $\begin{array}{l}\text { Detection accuracy in perimetry, } \\
\text { reaction time }\end{array}$ \\
\hline Sahraie (2006) & cortical blindness & $\begin{array}{l}\text { Visual detection training }(n=12) \\
\text { Daily for } 3 \text { months, RCS }\end{array}$ & $\begin{array}{l}\text { Detection accuracy, contrast } \\
\text { sensitivity, visual awareness, } \\
\text { threshold perimetry }\end{array}$ \\
\hline Kasten (1998) & $\begin{array}{l}\text { Post-chiasma \& optic } \\
\text { neuropathy }\end{array}$ & $\begin{array}{l}\text { VRT }(n=19) \text { vs. control group } \\
(n=19) 1 \text { hr./day for } 6 \text { months, } \\
\text { RCS }\end{array}$ & $\begin{array}{l}\text { Detection accuracy, visual field } \\
\text { border shift }\end{array}$ \\
\hline Jobke (2009) & Post-chiasmatic & $\begin{array}{l}\text { extra-striate VRT vs. standard VRT } \\
(n=18) \text { in a cross-over study } \\
(n=8 / 10), \text { RCS }\end{array}$ & $\begin{array}{l}\text { Detection accuracy, letter } \\
\text { identification, threshold perimetry, } \\
\text { quality of life measures }\end{array}$ \\
\hline Poggel (2004) & Post-chiasmatic & $\begin{array}{l}\text { Attention cue VRT ( } n=9) \text { vs. } \\
\text { standard VRT }(n=10), \text { RCS }\end{array}$ & $\begin{array}{l}\text { Detection accuracy, threshold } \\
\text { perimetry, visual field size }\end{array}$ \\
\hline Dundon (2015) & Post-chiasmatic & $\begin{array}{l}\text { Visual stimulation combined with } \\
\text { auditory cuing ( } n=8,4 \text { hrs. daily } \\
\text { for } 2 \text { weeks), RCS }\end{array}$ & visual detection and exploration \\
\hline
\end{tabular}

Brain current stimulation

$\begin{array}{ll}\text { Sabel (2011a) } & \text { Optic Neuropathy } \\ \text { Gall (2011) } & \text { Opticus-Neuropathy } \\ \text { Gall (2016) } & \begin{array}{l}\text { Opticus-Neuropathy } \\ \text { /glaucoma } \\ \text { Opticus-Neuropathy } \\ \text { /glaucoma }\end{array}\end{array}$

$\operatorname{ACS}(n=12)$ vs. control $(n=10) ; 10$ Tage for 20-40 min., RCS

$\operatorname{ACS}(n=24)$ vs. control $(n=18), 10$ Tage à 20-40 min., RCS

ACS $(n=49)$ vs. control $(n=37), 10$ Tage à 20-40 min., RCS

Direct current plus VRT vs. VRT alone $(n=8) 3 \times 1 \mathrm{hr}$./week, for 3 months), RCS
Detection accuracy, reaction time, threshold perimetry, near- and far-vision

Detection accuracy, visual field size, foveal threshold

Detection accuracy, foveal $\left(5^{\circ}\right)$ threshold

Visual field expansion, activities of daily living

\section{Drugs}

$\begin{array}{cccc}\text { Flammer (1983a) } & \text { Early glaucoma } & \begin{array}{c}\text { Acetazolamide } 3 \times 250 \mathrm{mg} \text { Tablets } \\ \text { over } 12 \mathrm{hrs} \text {; Single case, studied } \\ \text { twice with } 5 \text { months interval } \\ \text { Konieczka (2016c) }\end{array} & \begin{array}{c}\text { Perimetric threshold at 24 hrs. after } \\ \text { each of the two test which were } 5 \\ \text { months apart }\end{array} \\ \begin{array}{l}\text { POAG \& ON compartment }(n=7), \text { low dose calcium } \\ \text { channel blocker (nifedipine, } \\ \text { amlodipine) and magnesium }\end{array} & \begin{array}{c}\text { Optic nerve width, assessed by eye } \\ \text { socket echography; perimetry } \\ \text { (only single case) }\end{array}\end{array}$

Abbreviations: PAOG (primary open angle glaucoma), ACS (alternating current stimulation), DCS (direct current stimulation), VRT (vision restoration training), RCS (randomized, controlled study).

function, but these studies used training paradigms that were either too short (Balliett, Blood \& Bachy-Rita, 1985) or too difficult (Reinhard et al., 2005, Roth et al., 2009). Criticisms that eye movement artefacts are responsible for apparent, but not real, visual field improvements were raised, but they did not stand the test of experimental verification (Kasten, Bunzenthal \& Sabel, 2006; Kasten, Guenther \& Sabel, 2008). For a recent review on this topic, see Matteo, Viganò, Cerri \& Perin (2016) and de Haan, Heutink, Melis-Dankers \& Tucha (2014).

\subsection{Brain networks, synchronization and amplification}

Normal visual perception requires the interaction of many brain structures, not just the activity of a few local regions, such as the primary visual cortex. Vision is rather the product of both local and global mechanisms in the brain. Through complex interactions among different visual and nonvisual structures, conscious visual experience is the result of synchronized mental activity among these 
different systems (Uhlhaas \& Singer, 2006), and its expression is dependent on visually-elicited (motor) responses and cognitive processing. As Palva and Palva (2017) point out, it is through neuronal oscillations of brain networks that synchronization between different brain areas takes place. This allows the coordination of neuronal communication in a distributed brain network, and it is by way of cross-frequency phase synchrony (coupling) that oscillatory activity of different phases and frequencies are coordinated to permit the interactions of different functions and modalities, linking, for example, sensory information with attentional and executive control.

What does that mean practically? Even a most simple dot detection task, as used in perimetry, involves the interaction of a host of different brain structures and functions: in the eye, on the one hand, photons are translated into neurophysiological impulses and pre-processed by retinal mechanisms, travelling through the optic nerve to the brain. On the brain-side, the situation is much more complex, because visual perception requires (i) sufficient vigilance (being "awake"), (ii) motivation ("I want to do the test"), (iii) attention to the task ("concentrate on detecting the target dots"), (iv) fixating (“keep your eyes steady"), (v) Gestalt perception ("identifying the shape of a dot"), (vi) visual memory ("remember the dot"), (vii) cognitive decision making ("it was the target") and, finally, (viii) a motor response ("move the finger to press the button"). Other modulating factors are (ix) anxiety, (x) responses biases, and (xi) response fluctuations (Flammer, Drance \& Zulauf, 1984c) due to vascular status, time of day or even weather conditions (atmospheric pressure).

Therefore, whatever number of residual visual signals arrive in the brain, the question is: how can the brain network amplify and interpret them in a holistic context with all its functions and sub-functions, to execute a (motor) response? Each of the many sensory and neuropsychological functional circuits needs to be properly synchronized in time and space to achieve a visual evoked network response within a short time of 200-500 msec (Bola \& Sabel, 2015; Hadid \& Lepore, 2017). This is achieved by the interaction of many different brain structures. As Figure 4 and Table 2 show, the execution of visually elicited perception and behaviour is an affair of many different structures within a complex vision network comprised of the retina in the eye, subcortical structures, and cortical areas of the brain which interact with other important brain regions, like the frontal cortex. The list in Table 2, which is not exhaustive, serves to illustrate the important role of different brain regions in processing normal vision and Fig. 2 shows the many different psychological modulators of the brain affecting visual performance.

This complex interaction among different brain regions needs to be synchronized for vision to function properly (Fig. 4). But when the brain network is de-synchronized (Fig. 5), for example by distractions, lack of attention, fatigue or because of morphological damage (Bola et al., 2015), visually guided performance may be impaired (for example in glaucoma or optic neuropathy). Thus, vision loss is a combination of both, the tissue damage ("anatomical" loss or hypomethabolic state) plus any alterations in the brain network organization and synchronization ("functional" loss). Even a perfectly normal retinal signal may not be properly recognized by the brain if the brain network is desynchronized. Especially areas of residual vision, known as relative scotomas, are susceptible to many such influences which easily cause response fluctuations due to alterations in blood flow regulation, disorganization of connectivity networks and so on (Flammer et al., 1984a, b; Bola et al., 2015). Even if the damaged retinal tissue cannot be fixed, the brain network synchronization "behind the eye" lesion can be modulated - an opportunity for recovery of vision (Connell \& Merabet, 2014; Bola et al., 2014).

To understand mechanisms of vision recovery and rehabilitation, the brain's network state needs to be better understood to be able to learn whether functional changes are due to the formation of new connections, or due to functional recruitment of existing pathways (or a combination of the two). Cowey and colleagues (Bridge, Thomas, Jbabdi \& Cowey, 2008) studied this topic in blindsight patients probing connectivity after visual cortex lesions. They found that alternative brain regions processing visual information were used following cortical damage (in this case, since childhood) as documented by MRI evidence of a contralateral LGN->V5 pathway and bilateral cortico-cortical V5 connections, both of which were not seen in normal controls.

\subsection{Brain network reorganization after brain current stimulation}

Brain functional reorganization is thus a potential mechanism to amplify residual vision even in the absence of regenerating cells or axons. Just as a microphone problem can be compensated for by modulating the signal with an amplifier that filters 


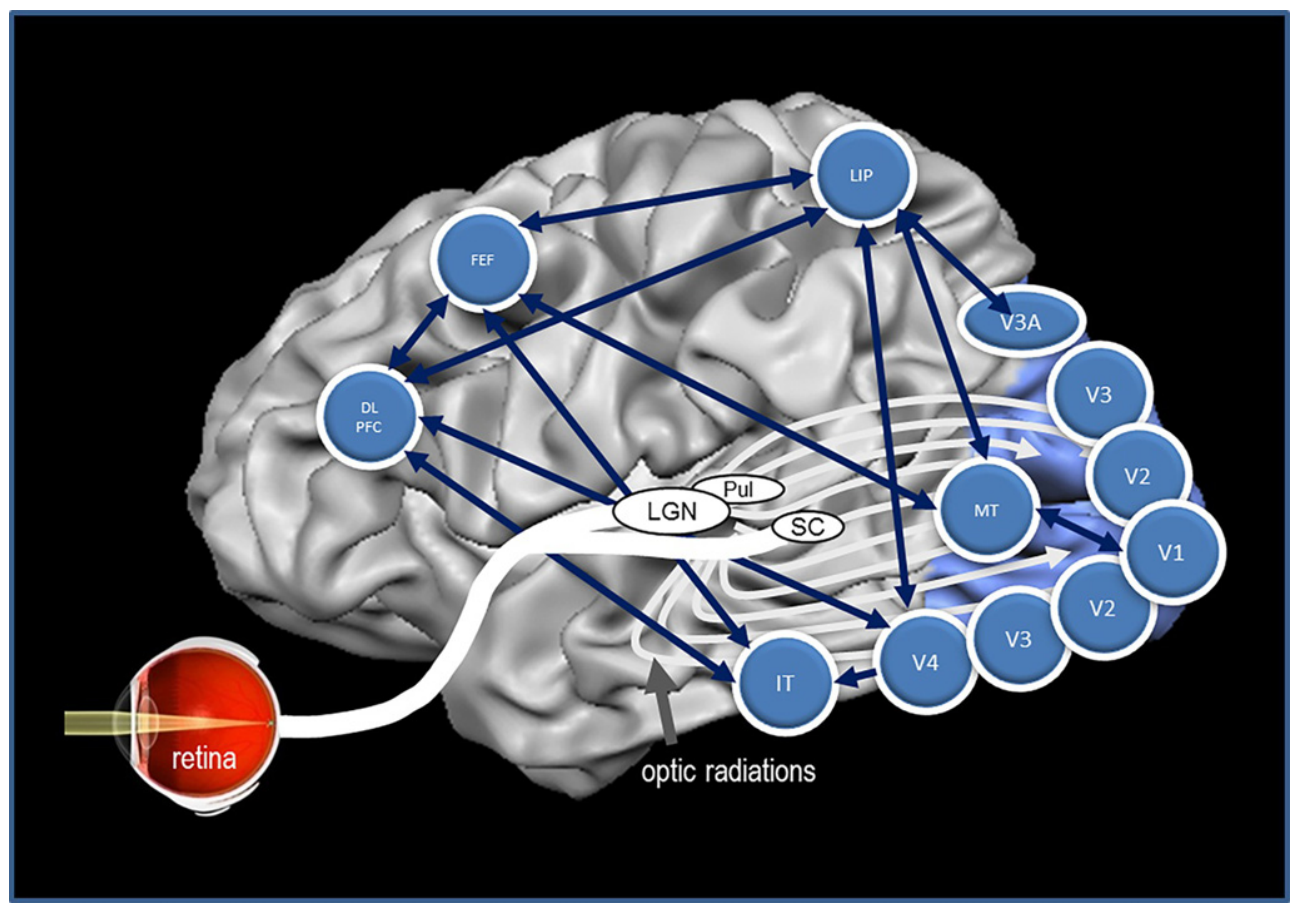

Fig. 4. The brain's network to control vision. Many structures of the brain need to interact synchronously to execute visually elicited performance. The vision network is comprised of the retina, subcortical structures, and cortical areas of the brain with multiple interactions with each other. This graph depicts some of the most important brain regions and their presumed functions. The structures and some of their main functions are depicted in Table 2 .

Table 2

Brain structures of vision. This Table illustrates how different visual areas are involved in different functions and sub-function sub serving sensory, cognitive and executive functions involved in visually elicited behaviour

\begin{tabular}{lll}
\hline Structure & Abbr. & Function \\
\hline Retina & Ret & phototransduction, preprocessing \\
Optic nerve & ON & signal transfer to brain \\
Lateral geniculate & LGN & bundles different functional channels \\
Suprachiasmatic nucleus & SCN & circadian rhythm control \\
Pulvinar nucleus & Pul & orchestrates neural processing of cortex \\
superior colliculus & SC & sensorimotor integration, orientation \\
primary visual cortex & V1 & feature analysis (pixels and edges) \\
area V2 & V2 & binocularity \\
area V3/V3A & V3/V3A & global motion \\
area V4 & V4 & color processing \\
inferior temporal cortex & IT & object identification (e.g. faces) \\
middle temporal cortex & MT (or V5) & motion perception and integration \\
lateral intraparietal cortex & LIP & eye movements (saccades) \\
frontal eye field & FEF & visual attention \& voluntary eye movements \\
dorsal lateral prefrontal cortex & DLPFC & executive functions and planning \\
\hline
\end{tabular}

out noise or increases its volume, it is the deafferented brain network "behind" the zone of damage which has an untapped potential to recover vision by strengthening and interpreting the visual signals better again. A de-synchronized brain network fails to sufficiently "amplify" residual visual signals whereas a synchronized network can elevate them above the threshold of conscious perception (Fig. 5). If and how well residual vision is consciously perceived depends on both local and global (downstream) brain network mechanisms. The long-range alpha-synchronization connecting occipital and frontal cortical regions seems to be a key in the vision recovery process (Fig. 6) (Sabel et al., 2011b; Bola et al., 2014). 

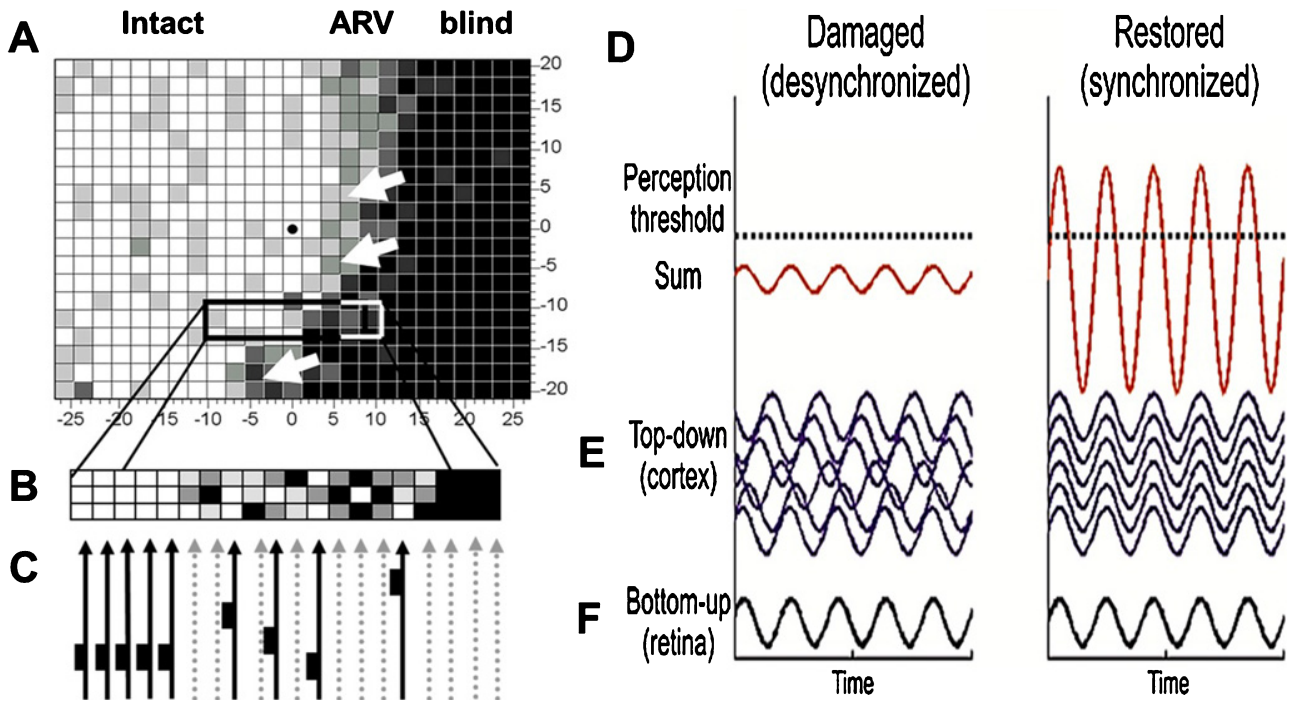

Fig. 5. Residual vision and brain network amplification. (A) This graph serves only as a conceptual guide to appreciate the nature of residual vision and the interactions of retina and brain by neuronal oscillatory activity. Accordingly, vision loss (e.g. measured by detection ability) depends on how many cells are lost: the greater the cell loss, the greater is the defect in different regions of the visual field. Areas of residual vision (ARVs; shown in grey) correspond to regions of partial damage with or without vascular dysregulation. They are found in all kinds of visual field defects such as after stroke (e.g. hemianopia) or retinal or optic nerve damage (e.g. glaucoma). Black areas represent complete damage. Note, however, that many black regions may, in fact, have some residual visual function as well. (B) Whether or not visual stimuli processes by the retina are consciously perceived by the brains is not only determined by the strength of the neuronal signals sent by the retina to the brain, but it also depends on how the brain processes this information through synchronization, amplification and interpretation. Neural activity of the retina is represented here by a simple sine wave. If the brain network is disorganized (illustrated here by non-synchronized, out-of-phase brain sine waves), the sum of retinal and brain signals is too low to surpass the perceptual threshold and the visual stimulus is not perceived. When the brain is synchronized, this elevates (amplifies) the same residual visual signal to above-threshold perception, thus improving or restoring conscious vision.

One opportunity to modify brain connectivity is by way of treating patients with alternating current stimulation (ACS) (sometimes also referred to as transorbital, transcranial, or transpalpebral stimulation). ACS aims at activating residual vision and improve visual fields (Sabel et al., 2011b; Bola et al., 2014; Gall et al., 2016) (Fig. 7). After optic nerve damage, for example ACS treatment for ten days can improve functional connectivity networks in the alpha-frequency range (Bola et al., 2014) and enlarge visual fields. This was shown with several studies in Germany (Gall et al., 2011; Sabel et al., 2011b; Gall et al., 2016), Russia (Shandurina \& Panin, 1990) and Japan (Fujikado et al., 2006) including small trails with nonarteritic ischemic neuropathy, primary open angle glaucoma, retinal artery occlusion and retinal dystrophies (Gall et al., 2011; Sabel et al., 2011b; Gall et al., 2016), macular degeneration (Anastassiou et al., 2013), and retinitis pigmentosa (Schatz et al., 2011, Bittner \& Seger 2018). In hemianopia after stroke also direct current stimulation has been used (Halko et al., 2011; Plow, Obretenova, Fregni, Pascual-Leone \& Merabet, 2012). Indeed, the approach to treat vision loss with electric current is not new: almost 150 years ago vision recovery following electric stimulation was already published in Germany (Erb, 1882; Mann, 1904).

The proposed mechanism of ACS action is a "learning-like" synaptic strengthening by repetitive activation of residual neurons in the brain's network. ACS is applied near the eyes which forces RGCs to fire in the rhythm of the ACS frequency band (Herrmann, Rach, Neuling \& Strüber, 2013; Foik et al., 2015). In this way brain oscillations may be modulated and their repetitive use leads to long-lasting changes ("long-term potentiation") which outlasts the time of stimulation ("after-effect") (Sabel et al., 2011a; Herrmann et al., 2013). By way of this brain modulation (synchronization), residual vision is strengthened through network reorganization which correlates with the extent of visual field improvements (Sabel et al., 2011a; Bola et al., 2014). This is not proof of causality that network reorganization is the only cause of recovery; both may have a common (third) mechanism, for example, blood flow changes. In any event, if no morphological regen- 

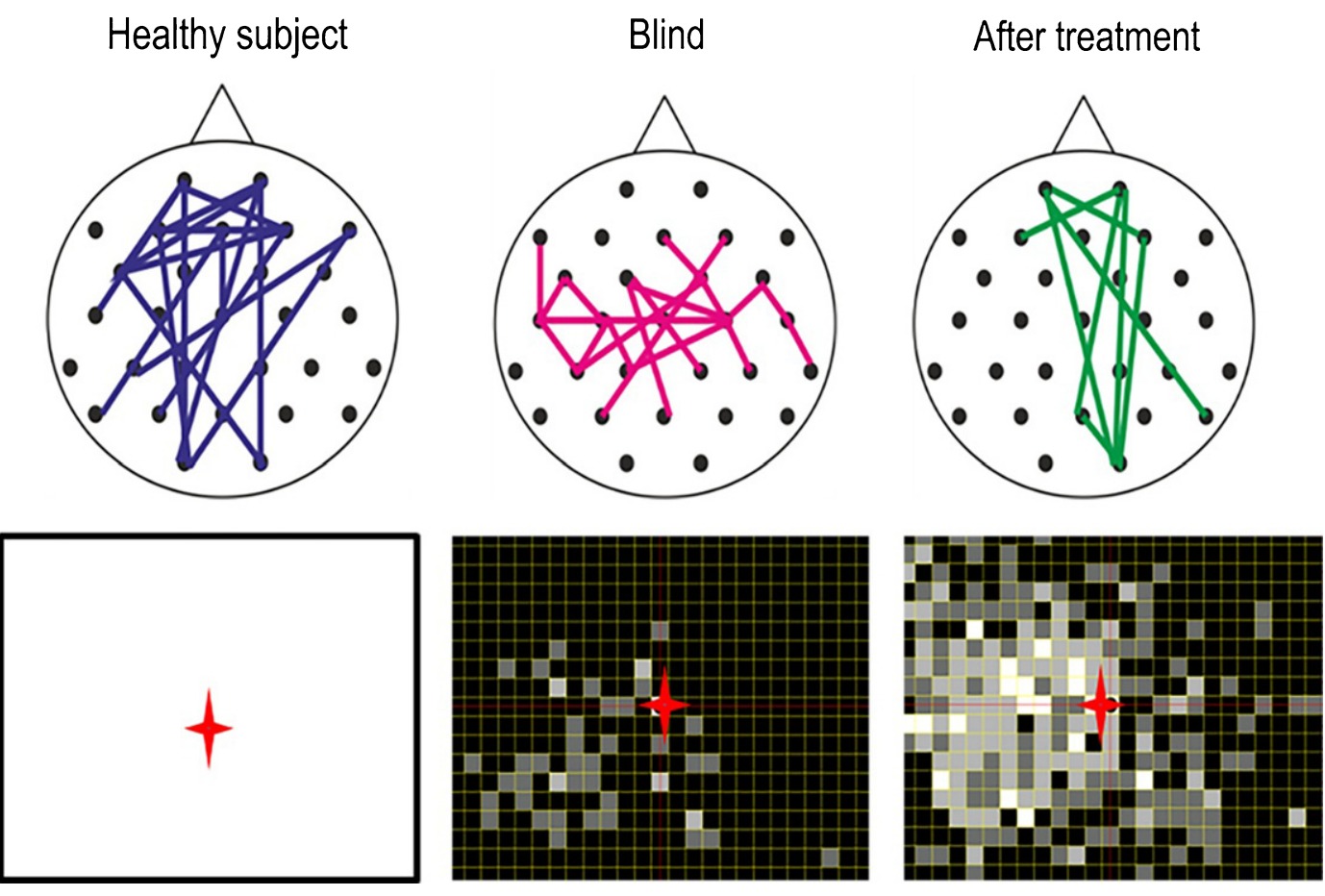

Fig. 6. Brain functional network reorganization. Healthy subjects have a strong functional connectivity network between occipital and frontal regions of the brain. But in patients with visual field defects this network is lost. When treated for 10 days with alternating current stimulation, this network is partially restored (Bola et al., 2014). Lower panel: As the brain functional connectivity recovers, so does the visual field (shown here with supra-threshold campimetry) (Sabel, 2016).

eration happens, visual field loss can still partially recover through plasticity and network synchronization by brain "amplification", increasing the brain's responsiveness to residual signals.

And there are other neuroprotective mechanisms that may contribute to the effects of electric current stimulation, including increased fibroblast growth factor beta, insulin-like growth factor-1, ciliary nerve trophic factor, and brain-derived neurotrophic factor (Morimoto et al., 2005; Yin et al., 2016; HenrichNoack, Sergeeva \& Sabel, 2017), for review see Henrich-Noack et al., 2017) and down-regulation of proinflammatory cytokines, such as interleukin-1 beta, tumor necrosis factor alpha, and the proapoptotic gene Bax (Zhou et al., 2012; Tao et al., 2016; Yin et al., 2016).

Recent exploratory studies (Gall et al., 2011; Sabel et al., 2011b) and a confirmatory multi-center, randomized trial (Gall et al., 2016) have documented the feasibility, safety and efficacy of ACS to improve visual fields, reaction time, acuity and quality of life measures in patients with glaucoma and optic nerve damage. The average improvement varies from 20$40 \%$ change over baseline (Sabel et al., 2011a) which is roughly in the range of normal perceptual learn- ing (Sabel et al., 2011a; Otto \& Michelson, 2014) and vision restoration training effects (Kasten et al., 1998). After ACS patients report improved reading, mobility, visual field expansion, contrast sensitivity, acuity and less foggy vision or glare (Gall et al., 2011). However, vision restoration varies between patients, the cause(s) of which is unknown, and there are approximately $20-30 \%$ non-responders which is also found in the vision training studies.

In both, the behavioral training or the ACS stimulation, vision restoration is not expected to completely normalize vision as primary damage with cell death can never be reversed. Interestingly, efficacy in both approaches is not related in a major way to patient's age, the age of the vision loss or its etiology, though this requires further study. The only obvious predictor of outcome known so far is the size of the relative scotoma (residual vision) (Sabel et al., 2011a).

\subsection{Drugs for visual field improvement}

Some exploratory reports show that certain drugs might be able to improve visual fields. Though the studies were not randomized trials, they still offer some clues for future research: FS patients 

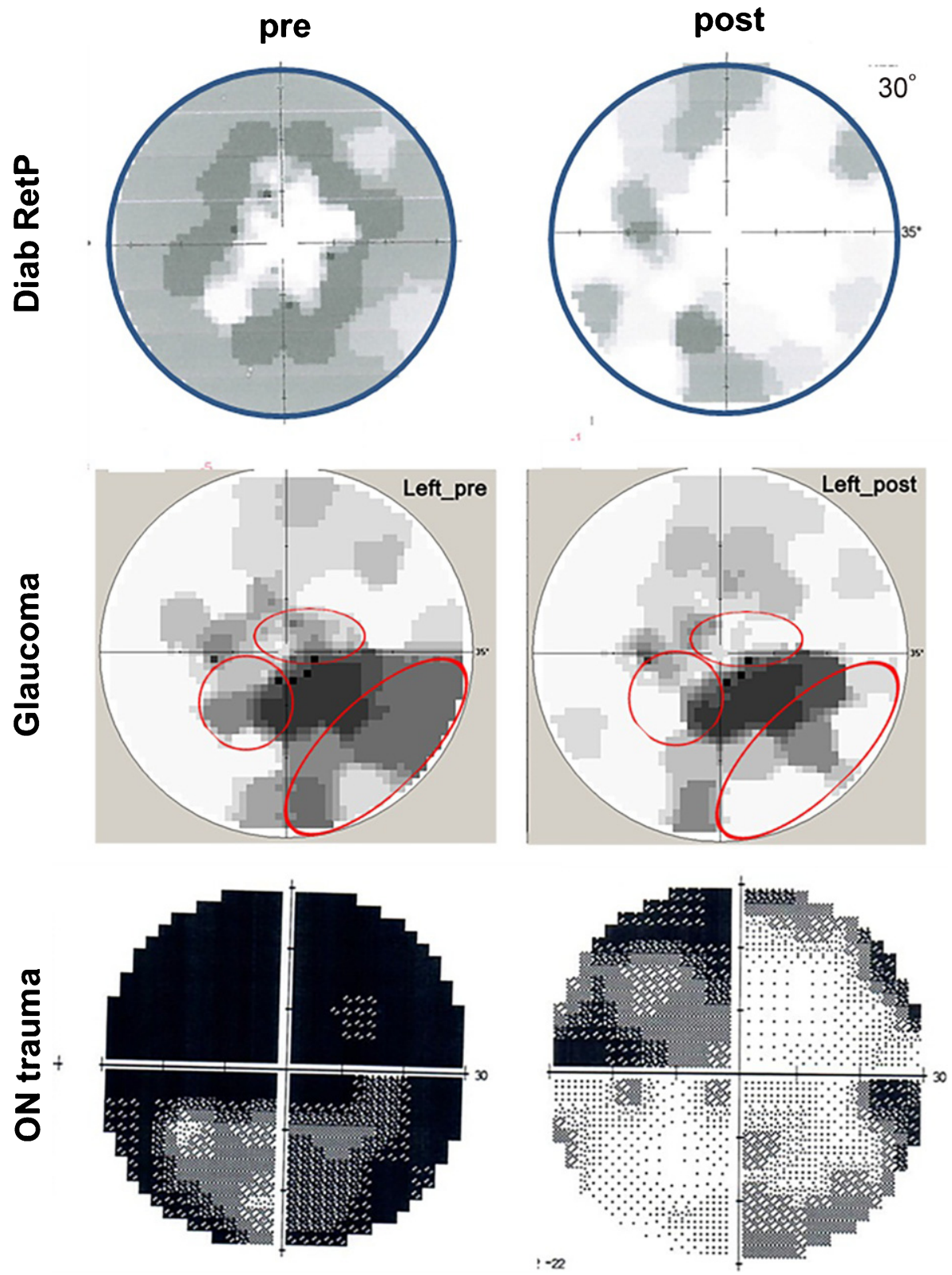

Fig. 7. Activating residual vision. Examples of visual field recovery of three patients before and after treatment with alternating current stimulation (ACS); Top and middle panel: visual fields of a case with diabetic retinopathy and open-angle glaucoma before and after 10 days. The visual fields on the bottom is from a 27 year old male suffering from traumatic brain and optic nerve damage before and after 10 days of ACS with an additional 3 months of relaxation and eye yoga exercises. Note that visual field recovery emerges mostly from the grey regions (relative scotomas or "areas of residual vision"). Red circles indicate regions of vision recovery.

treated with calcium channel blockers (nifedipine or amlodipine) (Gasser \& Flammer, 1990; Konieczka et al., 2016c) or acetazolamide (Flammer \& Drance, 1983a, b) to increase blood flow who rapidly improved visual field function. Drugs that improved the visual fields (VF) of glaucoma patients had the following characteristics and limitations: (i) the short-term changes were not related to IOP changes; (ii) one could observe threshold shifts in relative scotomas (best seen with the help of the Bebie curve), but very rarely - though occasionally - changes in the size of absolute scotomas, (iii) all the drugs that improved VF had in common that they improved blood flow in the eye (and probably also in the brain), and (iv) 
improvements were more likely seen in FS+ but only infrequently in FS- cases (Flammer \& Konieczka, 2017).

\section{A neurovascular hypothesis of residual vision activation and restoration}

In the present paper, we have discussed three fundamental topics: the brain-eye-vascular triad, residual vision and its activation, and visual system plasticity (Fig. 1). These fields are interconnected as the following hypothesis outlines.

To process visual information, neurons of the visual pathway need to process and transmit electrophysiological information from the eye to the brain and within the brain by firing action potentials. Without visual stimulation, neurons are in a "resting state", firing action potentials only intermittently and at low rates. However, when visual stimuli need to be processed (for example when there is flickering light), neurons are activated and fire action potentials much more rapidly. This, however, requires a healthy cellular state and immediate upstream dilation of blood vessels to increase oxygen and glucose supply. Neurovascular coupling (NC) is the mechanism whereby neural activity and upstream vessel dilation are synchronized so that sufficient oxygen and glucose levels reach the firing neurons. A key signal responsible for this upstream vessel dilation is extracellular potassium which is elevated in the extracellular space when neurons fire and which, through capillary potassiumsensing, initiates retrograde hyperpolarization. Since potassium ions are charged, it is an "electric" signal that triggers upstream dilation (Longden et al., 2017).

But if vascular coupling is impaired, we propose this can especially impact very small microvessels like those found in the eye, inner ear, or brain. Vascular dysregulation (besides arteriosclerosis or vessel inflammation) then deprives neurons of oxygen and glucose and they get locked-in ("silenced") in a hypo-metabolic state. Neurons are then unable to fire action potentials at sufficient rates and/or durations to propagate a visual impulse. Though these cells are too healthy to die ("silent survivors"), they survive but are unable to fire action potentials, leading to a functional impairment.

We propose that areas of residual vision as outlined above suffer not only from partial cell death, but contain many cells which are silent survivors which - because of cellular or metabolic stress and lack of energy (oxygen and glucose) remain dormant for a long time (years). Visual field regions with such residual capacities appear to be blind perimetrically, but they provide an untapped potential. Activating these silent survivors shows that there is more vision potential behind the "black curtain" of blindness, but vision improvement is possible using by visual training, medications, or electrical stimulation. Interestingly, all these three therapies have one thing in common: they improve blood flow. Visual training activates neurons to fire visual impulses and thus provokes blood flow locally, medications improve blood flow by pharmacological means, and electrical stimulation using alternating currents stimulates neuronal firing and it mimics the endogenous electric mechanism of dilation directly. This proposal is compatible with the "residual visual activation theory" (Sabel et al., 2011a) and explains the following observations. (i) Behavioural training takes a long time because each small training stimulus (dot) excites only a small region of the retina, (ii) drug treatment can instantaneously improve visual fields, and (iii) alternating current stimulation forces all surviving neurons to fire with rapid improvements in only a few days of treatment.

This cellular scenario is of relevance for regions of the visual system directly damaged by the pathology, but also for down-stream neuronal networks of the brain. Healthy neurovascular coupling is therefore critical for all visual functions and sub-functions, and without it there may be no plasticity.

To sum up, here we propose that vascular dysregulation is both the problem and the solution of vision loss. We believe that it is a fundamental mechanism of restoration and neural recovery with a system-wide impact on neuronal reserve function. Further studies are now needed to substantiate this hypothesis to determine (i) if, or to what extent, vascular dysregulation is rate-limiting for neuronal activation because of silencing neurons, (ii) how vascular dysregulation affects sensory-cognitive interactions, and (iii) how treatment of it can reverse hypo-metabolic states, providing a possible source of sensory-cognitive recovery and reserve.

\section{Conclusions and perspectives}

A better knowledge of the many interactions between the eye, brain, and cardiovascular system are key for a better understanding of how to treat 
vision loss. Exploring these interactions in the braineye-vascular triad (Fig. 1) will not only better explain different pathological conditions, but it may also shed more light on hitherto unexplained phenomena in clinical care (such as fluctuating and/or recoverying visual fields).

The brain has many direct and indirect influences on eye diseases: direct influences are (i) the amplification of (residual) retinofugal impulses, (ii) the modification and interpretation via top-down influences (e.g. cognition, attention, emotion), and (iii) the control of eye movements. Indirect influences are (v) the modification of the vascular system through stress hormones and their impact at different levels of the vascular physiology, (vi) the nervous system, (vii) the CSF pressure conditions, and, finally, (viii) their relation to emotional states (stress, anxiety).

A more holistic medical and psychological approach to VI is needed to address these different mechanisms of vision loss. This more holistic approach might help pave the way for a fresh new perspective of how to modulate multiple mechanisms, an untapped potential for innovation in technology and patient care. We need to grasp the meaning of vision impairments in neurological diseases on the one hand and appreciate the brain's contribution in "visual" (eye) disorders on the other hand, particularly their role in activating residual vision to achieve recovery.

\section{Future directions}

This new understanding of a possible interaction of brain plasticity and vascular dysregulation in vision recovery is a starting point to conceive of and test novel therapeutic options to prevent disease progression and/or restore visual functions. We are at the beginning of a journey that includes the science of both brain physiology and vascular regulation in understanding and treating low vision.

Here are some suggestions for future directions:

- Further explore the role of transmodal brain plasticity to compensate for VI;

- Study hypo-metabolic mechanisms of cell inactivation ("silent" neurons);

- Search for both local (at or near the site of damage) and global mechanism of recovery of vision, e.g. brain functional networks and vascular system modulations.

- Study the mechanisms of vision training and brain current stimulation with regard to their impact on residual vision activation and its relationship to regional and whole brain network synchronization and reorganization;

- Explore the potential to normalize vascular dysregulation by way of drugs or other means;

- Evaluate psychological treatments for stressreduction such as relaxation techniques like meditation and yoga, physical exercise, and psychotherapeutic interventions and determine their impact on visual field fluctuations and visual field recovery;

- Develop holistic concepts for the treatment of low vision that are complementary to eye drops or surgery and integrate the medical and psychological state of the patient, including questions related to emotions and lifestyles, issues which are seldom addressed (Stew, 1997).

We should have an open mind that neurology, neuroscience and psychology could assist ophthalmology to advance the field with a fresh new look at the brain-eye-vascular triad. A more holistic approach to vision loss will unveil new treatment options based on combined medical/psychological concepts that follow a more global and not just an eye-centric perspective. Vision loss is a holistic matter and the brain not just an "appendix" of the eye. There is clearly more wiggle room to improve visual field defects and patient care and there is more light at the end of the tunnel. The human suffering and the burden to society inflicted by blindness justifies that fields outside of ophthalmology, such as neuroscience/neurology and psychology, help push the mission forward to restore vision and improve quality of life. In this regard, the brain deserves a better reputation for its role in ophthalmologic diseases of the "person behind the eye".

\section{References}

AFB. Senior Site Press Release Archive. American Foundation for the Blind Launches Web Site to Help People with Vision Loss Maintain Independence. http://www.afb.org/info/programsand-services/professional-development/experts-guide/pressrelease-archive-3641/1235 (accessed 03.04.2007).

Amedi, A., Raz, N., Pianka, P., Malach, R. \& Zohary, E. (2003). Early 'visual' cortex activation correlates with superior verbal memory performance in the blind. Nature Neuroscience, 6 , 758-766.

Amedi, A., Floel, A., Knecht, S., Zohary, E. \& Cohen, L.G. (2004). Transcranial magnetic stimulation of the occipital pole interferes with verbal processing in blind subjects. Nature Neuroscience, 7, 1266-1270. 
Anastassiou, G., Schneegans, A.L., Selbach, M. \& Kremmer, S. (2013). Transpalpebral electrotherapy for dry age-related macular degeneration (AMD): An exploratory trial. Restorative Neurology and Neuroscience, 31, 571-578.

Armstrong, R.A. (2011). Visual signs and symptoms of progressive supranuclear palsy. Clinical \& Experimental Optometry, 94, $150-160$.

Armstrong, R. \& Kergoat, H. (2015). Oculo-visual changes and clinical considerations affecting older patients with dementia. Ophthalmic \& Physiological Optics, 35, 352-376.

Armstrong, R.A. \& Syed, A.B. (1996). Alzheimer's disease and the eye. Ophthalmic \& Physiological Optics, 16, S2-8.

Backon, J., Matamoros, N., Ramirez, M., Sanchez, R.M., Ferrer, J., Brown, A. \& Ticho, U. (1990). A functional vagotomy induced by unilateral forced right nostril breathing decreases intraocular pressure in open and closed angle glaucoma. British Journal of Ophthalmology, 74, 607-609.

Baertschi, M., Dayhaw-Barker, P. \& Flammer, J. (2016). The effect of hypoxia on intra-ocular, mean arterial, retinal venous and ocular perfusion pressures. Clinical Hemorheology and Microcirculation, 63, 293-303.

Balliett, R., Blood, K.M. \& Bach-y-Rita, P., (1985). Visual field rehabilitation in the cortically blind? Journal of Neurology, Neurosurgery, and Psychiatry, 48, 1113-1124.

Bauer, C.M., Hirsch, G.V., Zajac, L., Koo, B.B., Collignon, O. \& Merabet, L.B. (2017). Multimodal MR-imaging reveals large-scale structural and functional connectivity changes in profound early blindness. PLoS One, 12, e0173064.

Bedny, M., Pascual-Leone, A., Dodell-Feder, D., Fedorenko, E. \& Saxe, R. (2011). Language processing in the occipital cortex of congenitally blind adults. Proceedings of the National Academy of Sciences of the United States of America, 108, 4429-4434.

Benowitz, L.I., He, Z. \& Goldberg, J.L. (2017). Reaching the brain: Advances in optic nerve regeneration. Experimental Neurology, 287, 365-373.

Berdahl, J.P., Allingham, R.R. \& Johnson, D.H. (2008). Cerebrospinal fluid pressure is decreased in primary open-angle glaucoma. Ophthalmology, 115, 763-768.

Bittner, A.K. \& Seger, K. (2018). Longevity of visual improvements following transcorneal electrical stimulation and efficacy of retreatment in three individuals with retinitis pigmentosa. Graefe's Archive for Clinical and Experimental Ophthalmology, 256, 299-306.

Black, P. (1982). Visual disorders associated with cerebral palsy. British Journal of Ophthalmology, 66, 46-52.

Bodis-Wollner, I. (1990). The visual system in Parkinson's disease. Research publications - Association for Research in Nervous and Mental Disease, 67, 297-316.

Bojinova, R.I., Konieczka, K., Meyer, P. \& Todorova, M.G. (2016). The trilateral link between anaesthesia, perioperative visual loss and Flammer syndrome. BMC Anesthesiology, 16, 10.

Bola, M. \& Sabel, B.A. (2015). Dynamic reorganization of brain functional networks during cognition. Neuroimage, 114, 398413.

Bola, M., Gall, C. \& Sabel, B.A. (2013). "Sightblind": Perceptual deficits in the "intact" visual field. Frontiers in Neurology, 4, 80
Bola, M., Gall, C. \& Sabel, B.A. (2015). Disturbed temporal dynamics of brain synchronization in vision loss. Cortex, 67 , 134-146.

Bola, M., Gall, C., Moewes, C., Fedorov, A., Hinrichs, H. \& Sabel, B.A. (2014). Brain functional connectivity network breakdown and restoration in blindness. Neurology, 83, 542-551.

Bolognini, N., Rasi, F., Coccia, M. \& Ládavas, E. (2005). Visual search improvement in hemianopic patients after audio-visual stimulation. Brain, 128, 2830-2842.

Bosking, W.H., Beauchamp, M.S. \& Yoshor, D. (2017). Electrical Stimulation of Visual Cortex: Relevance for the Development of Visual Cortical Prosthetics. Annual Review of Vision Science, 3, 141-166.

Bourne, R.R.A., Flaxman, S.R., Braithwaite, T., Cicinelli, M.V., Das, A., Jonas, J.B., Keeffe J., Kempen, J.H., Leasher, J., Limburg, H., Naidoo, K., Pesudovs, K., Resnikoff, S., Silvester, A., Stevens, G.A., Tahhan, N., Wong, T.Y. \& Taylor, H.R., Vision Loss Expert Group (2017). Magnitude, temporal trends, and projections of the global prevalence of blindness and distance and near vision impairment: A systematic review and meta-analysis. The Lancet Global Health, 5, e888897.

Boyers, L.N., Karimkhani, C., Hilton, J., Richheimer, W. \& Dellavalle, R.P. (2015). Global burden of eye and vision disease as reflected in the Cochrane Database of Systematic Reviews. JAMA Ophthalmology, 133, 25-31.

Bridge, H., Thomas, O., Jbabdi, S. \& Cowey, A. (2008). Changes in connectivity after visual cortical brain damage underlie altered visual function. Brain, 131, 1433-1444.

Calkins, D.J., Pekny, M., Cooper, M.L. \& Benowitz, L. (2017). The challenge of regenerative therapies for the optic nerve in glaucoma. Lasker/IRRF Initiative on Astrocytes and Glaucomatous Neurodegeneration Participants. Experimental Eye Research, 157, 28-33.

Chen, S.P., Bhattacharya, J. \& Pershing, S. (2017). Association of Vision Loss With Cognition in Older Adults. JAMA Ophthalmology, 135, 963-970.

Chen, K.W., Berger, C.C., Manheimer, E., Forde, D., Magidson, J., Dachman, L. \& Lejuez, J.W. (2012). Meditative Therapies for Reducing Anxiety: A Systematic Review and Meta-analysis of Randomized Controlled Trials. Depression and Anxiety, 29, 545-562.

Cheng, D.L., Greenberg, P.B. \& Borton, D.A. (2017). Advances in Retinal Prosthetic Research: A Systematic Review of Engineering and Clinical Characteristics of Current Prosthetic Initiatives. Current Eye Research, 42, 334-347.

Chun, B.Y. \& Cestari, D.M. (2017). Advances in experimental optic nerve regeneration. Current Opinion in Ophthalmology, $28,558-563$.

Cohen, L.G., Celnik, P., Pascual-Leone, A., Corwell, B., Falz, L., Dambrosia, J., Honda, M., Sadato, N., Gerloff, C., Catalá, M.D. \& Hallett, M., (1997). Functional relevance of crossmodal plasticity in blind humans. Nature, 389, 180-183.

Collignon, O., Vandewalle, G., Voss, P., Albouy, G., Charbonneau, G., Lassonde, M. \& Lepore, F. (2011). Functional specialization for auditory-spatial processing in the occipital cortex of congenitally blind humans. Proceedings of the National Academy of Sciences of the United States of America, 108, $4435-4440$. 
Connell, N. \& Merabet, L.B., (2014). Uncovering the connectivity of the brain in relation to novel vision rehabilitation strategies. Neurology, 83, 484-485.

Costello, F., (2016). Vision Disturbances in Multiple Sclerosis. Semin Neurol, 36, 185-195.

Cotman, C.W. \& Berchtold, N.C. (2002). Exercise: A behavioral intervention to enhance brain health and plasticity. Trends in Neuroscience, 25, 295-301.

Dada, T., Mittal, D., Mohanty, K., Faiq, M.A., Bhat, M.A., Yadav, R.K., Sihota, R., Sidhu, T., Velpandian, T., Kalaivani, M., Pandey, R.M., Gao, Y., Sabel, B.A., Dada, R. (2018). Mindfulness Meditation Reduces Intraocular Pressure, Lowers Stress Biomarkers and Modulates Gene Ex-pression in Glaucoma: a randomized controlled trial. Journal of Glaucoma, in press.

Dagnelie, G. (2013). Age-related psychophysical changes and low vision. Investigative Ophthalmology and Visual Sciences, 54, ORSF88-93.

Dampney, R.A. (2015). Central mechanisms regulating coordinated cardiovascular and respiratory function during stress and arousal. American Journal of Physiology. Regulatory, Integrative and Comparative Physiology, 309, R429-443.

de Haan, G.A., Heutink, J., Melis-Dankers, B.J. \& Tucha, O. (2014). Brouwer WH. Spontaneous recovery and treatment effects in patients with homonymous visual field defects: A meta-analysis of existing literature in terms of the ICF framework. Survey of Ophthalmology, 59, 77-96.

de Lima, S., Habboub, G. \& Benowitz, L.I. (2012). Combinatorial therapy stimulates long-distance regeneration, target reinnervation, and partial recovery of vision after optic nerve injury in mice. International Review of Neurobiology, 106, 153-172.

Duncan, R.O., Sample, P.A., Weinreb, R.N., Bowd, C. \& Zangwill, L.M. (2007). Retinotopic organization of primary visual cortex in glaucoma: Comparing fMRI measurements of cortical function with visual field loss. Progress in Retinal and Eye Research, 26, 38-56.

Dundon, N.M., Ládavas, E., Maier, M.E. \& Bertini, C. (2015). Multisensory stimulation in hemianopic patients boosts orienting responses to the hemianopic field and reduces attentional resources to the intact field. Restorative Neurology and Neuroscience, 33, 405-419.

Engelhorn, T., Michelson, G., Waerntges, S., Struffert, T., Haider, S. \& Doerfler, A. (2011). Diffusion Tensor Imaging Detects Rarefaction of Optic Radiation in Glaucoma Patients. Acadademic Radiology, 18, 764-769.

Erb, W. (1882). Handbuch der Elektrotherapie. Verlag V.C.W. Vogel; Leipzig.

Erb, C., Batra, A., Lietz, A., Bayer, A.U., Flammer, J. \& Thiel, H.J. (1999). Psychological characteristics of patients with normal-tension glaucoma. Graefe's Archive for Clinical and Experimental Ophthalmology, 237, 753-757.

Fahle, M. (2002). Perceptual learning: Gain without pain? Nature Neuroscience, 5, 923-924.

Faiq, M.A., Dada, R., Kumar, A., Saluja, D. \& Dada, T. (2016). Brain: The potential diagnostic and therapeutic target for Glaucoma. Current Drug Targets, CNS and Neurological Disorders, 15, 839-844.
Fang, L., Baertschi, M. \& Mozaffarieh, M. (2014). The effect of flammer-syndrome on retinal venous pressure. BMC Ophthalmology, 14, 121.

Fernandes, R.A.B., Diniz, B., Ribeiro, R. \& Humayun, M. (2012). Artificial vision through neuronal stimulation. Neuroscience Letters, 519, 122-128.

Flammer, J. \& Drance. S.M. (1983a). Effect of acetazolamide on the differential threshold. Archives of Ophthalmology, 101, 1378-1380.

Flammer, J. \& Drance, S.M. (1983b). Reversibility of a glaucomatous visual field defect after acetazolamide therapy. Canadian Journal of Ophthalmology, 18, 139-141.

Flammer, J. \& Konieczka, K. (2015). Retinal venous pressure: The role of endothelin. EPMA Journal, 6, 21.

Flammer, J. \& Konieczka, K. (2017). The discovery of the Flammer syndrome: A historical and personal perspective. EPMA Journal, 8, 75-97.

Flammer, J., Drance, S.M. \& Fankhauser, F. (1984a). Differential light threshold. Short- and long-term fluctuation in patients with glaucoma, normal controls, and patients with suspected glaucoma. Archives of Ophthalmology, 102, 876-879.

Flammer, J., Drance, S.M. \& Schulzer, M. (1984b). Covariates of the Long-term Fluctuation of the Differential Light Threshold. Archives of Ophthalmology, 102, 880-882.

Flammer, J., Drance, S.M. \& Zulauf, M. (1984c). Differential light threshold. Short- and long-term fluctuation in patients with glaucoma, normal controls, and patients with suspected glaucoma. Archives of Ophthalmology, 102, 704-706.

Flammer, J., Konieczka, K. \& Flammer, A.J. (2013b). The primary vascular dysregulation syndrome: Implications for eye diseases. EPMA Journal, 4, 14.

Flammer, J., Pache, M. \& Resink, T. (2001). Vasospasm, its role in the pathogenesis of diseases with particular reference to the eye. Progress in Retinal and Eye Research, 20, 319-349.

Flammer, J., Orgül, S., Costa, V.P., Orzalesi, N., Krieglstein, G.K., Serra, L.M., Renard, J.P. \& Stefánsson, E. (2002). The impact of ocular blood flow in glaucoma. Progress in Retinal and Eye Research, 21, 359-393.

Flammer, J., Konieczka, K., Bruno, R.M., Virdis, A., Flammer, A.J. \& Taddei, S. (2013a). The eye and the heart. European Heart Journal, 34, 1270-1278.

Foik, A.T., Kublik, E., Sergeeva, E.G., Tatlisumak, T., Rossini, P.M., Sabel, B.A. \& Waleszczyk, W.J. (2015). Retinal origin of electrically evoked potentials in response to transcorneal alternating current stimulation in the rat. Investigative Ophthalmology and Visual Scinces, 56, 1711-1718.

Freund, H.-J., Sabel, B.A. \& Witte, O. (Eds.) (1997). Brain Plasticity. Lippincott/Raven Press.

Fujikado, T., Morimoto, T., Matsushita, K., Shimojo, H., Okawa, Y. \& Tano, Y. (2006). Effect of transcorneal electrical stimulation in patients with nonarteritic ischemic optic neuropathy or traumatic optic neuropathy. Japanese Journal of Ophthalmology, 50, 266-273.

Gall, C., Sgorzaly, S., Schmidt, S., Brandt, S., Fedorov, A. \& Sabel, B.A. (2011). Noninvasive transorbital alternating current stimulation improves subjective visual functioning and vision-related quality of life in optic neuropathy. Brain Stimulation, 4, 175-188. 
Gall, C., Schmidt, S., Schittkowski, M.P., Antal, A., Ambrus, G.G., Paulus, W., Dannhauer, M., Michalik, R., Mante, A., Bola, M., Lux, A., Kropf, S., Brandt, S.A. \& Sabel, B.A. (2016). Alternating current stimulation for vision restoration after optic nerve damage: A randomized clinical trial. PLoS One, 11, e0156134.

Gao, Y. \& Sabel, B.A. (2017). Microsaccade dysfunction and adaptation in hemianopia after stroke. Restorative Neurology and Neuroscience, 35, 365-376.

Gao, Y., Huber, C. \& Sabel, B.A. (2018). Stable microsaccades and microsaccade-induced alpha band phase reset across the life span. Investigative Ophthalmology and Visual Sciences, 59, 2032-2041.

Gasser, P. \& Flammer, J. (1986). Optic neuropathy of Graves' disease. A report of a perimetric follow-up. Ophthalmologica, 192, 22-27.

Gasser, P. \& Flammer, J. (1990). Short- and long-term effect of nifedipine on the visual field in patients with presumed vasospasm. The Journal of International Medical Research, $18,334-339$.

Gherghel, D., Orgül, S., Dubler, B., Lübeck, P., Gugleta, K. \& Flammer, J. (1999). Is vascular regulation in the central retinal artery altered in persons with vasospasm? Archives of Ophthalmology, 117, 1359-1362.

Gilbert, C.D. \& Wiesel, T.N. (1992). Receptive field dynamics in adult primary visual cortex. Nature, 356, 150-152.

Gnanalingham, K.K., Bhattacharjee, S., Pennington, R., Ng, J. \& Mendoza, N. (2005). The time course of visual field recovery following transphenoidal surgery for pituitary adenomas: Predictive factors for a good outcome. Journal of Neurology, Neurosurgery, and Psychiatry, 76, 415-419.

Gougoux, F., Zatorre, R.J., Lassonde, M., Voss, P. \& Lepore, F. (2005). A functional neuroimaging study of sound localization: Visual cortex activity predicts performance in early-blind individuals. PLoS Biology, 3, e27.

Grieshaber, M.C., Terhorst, T. \& Flammer, J. (2006). The pathogenesis of optic disc splinter haemorrhages: A new hypothesis. Acta Ophthalmologica Scandinavica, 84, 62-68.

Gupta, N., Ang, L.C., de Tilly, L.N., Bidaisee, L. \& Yucel, Y.H. (2006). Human glaucoma and neural degeneration in intracranial optic nerve, lateral geniculate nucleus, and visual cortex. British Journal of Ophthalmology, 90, 674-678.

Gupta, N., Yucel \& Y. H. (2007). Glaucoma as a neurodegenerative disease. Current Opinion in Ophthalmology, 18, 110-114.

Guthauser, U., Flammer, J. \& Mahler, F. (1988). The relationship between digital and ocular vasospasm. Graefe's Archive for Clinical and Experimental Ophthalmology, 226, 224-226.

Haas, A., Flammer, J. \& Schneider, U. (1986). Influence of age on the visual fields of normal subjects. American Journal of Ophthalmology, 101, 199-203.

Hadid, V. \& Lepore, F. (2017). From Cortical Blindness to Conscious Visual Perception: Theories on Neuronal Networks and Visual Training Strategies. Frontiers in Systems Neuroscience, 11, 64 .

Hadjinicolaou, A.E., Meffin, H., Maturana, M.I., Cloherty, S.L. \& Ibbotson, M.R. (2015). Prosthetic vision: Devices, patient outcomes and retinal research. Clinical \& Experimental Optometry, 98, 395-410.
Halko, M.A., Datta, A., Plow, E.B., Scaturro, J., Bikson, M. \& Merabet, L.B. (2011). Neuroplastic changes following rehabilitative training correlate with regional electrical field induced with tDCS. Neuroimage, 57, 885-891.

Hamilton, R., Keenan, J.P., Catala, M. \& Pascual-Leone, A. (2000). Alexia for Braille following bilateral occipital stroke in an early blind woman. Neuroreport, 11, 237-240.

Harwerth, R.S., Crawford, M.L.J., Frishman, L.J., Viswanathan, S., Smith, Earl L. III \& Carter-Dawson, L. (2002). Visual field defects and neural losses from experimental glaucoma. Progress in Retinal and Eye Research, 21, 91-125.

Henrich-Noack, P., Sergeeva, E. \& Sabel, B.A. (2017). Noninvasive electrical brain stimulation: From acute to late-stage treatment of CNS damage. Neural Regeneration Research, $12,1590-1594$

Herrmann, C.S., Rach, S., Neuling, T. \& Strüber, D. (2013). Transcranial alternating current stimulation: A review of the underlying mechanisms and modulation of cognitive processes. Frontiers in Human Neuroscience, 7, 279.

Hou, R., Zhang, Z., Yang, D., Wang, H., Chen, W., Li, Z., Sang, J., Liu, S., Cao, Y., Xie, X., Ren, R., Zhang, Y., Sabel, B.A. \& Wang, N. (2016). Intracranial pressure (ICP) and optic nerve subarachnoid space pressure (ONSP) correlation in the optic nerve chamber: The Beijing Intracranial and Intraocular Pressure (iCOP) study. Brain Research, 1635, 201-208.

Huxlin, K.R., Martin, T., Kelly, K., Riley, M., Friedman, D.I., Burgin, W.S. \& Hayhoe, M. (2009). Perceptual relearning of complex visual motion after V1 damage in humans. Journal of Neuroscience, 29, 3981-3991.

Jobke, S., Kasten, E. \& Sabel, B.A. (2009). Vision restoration through extrastriate stimulation in patients with visual field defects. Neurorehabilitation and Neural Repair, 23, 246-255.

Kanjee, R., Yücel, Y.H., Steinbach, M.J., González, E.G. \& Gupta, N. (2012). Delayed saccadic eye movements in glaucoma. Eye and Brain, 4, 63-68.

Kasten, E., Bunzenthal, U. \& Sabel, B.A. (2006). Visual field recovery after vision restoration therapy (VRT) is independent of eye movements: An eye-tracker study. Behavioural Brain Research, 175, 18-26.

Kasten, E., Guenther, T. \& Sabel, B.A. (2008). Inverse stimuli in perimetric performance reveal larger visual field defects: Implications for vision restoration. Restorative Neurology and Neuroscience, 26, 355-364.

Kasten, E., Wüst, S., Behrens-Baumann, W. \& Sabel, B.A. (1998) Computer-based training for the treatment of partial blindness. Nature Medicine, 4, 1083-1087.

Killer, H.E., Jaggi, G.P., Flammer, J., Miller, N.R., Huber, A.R. \& Mironov, A. (2007). Cerebrospinal fluid dynamics between the intracranial and the subarachnoid space of the optic nerve. Is it always bidirectional? Brain, 130, 514-520.

Kochkorov, A., Gugleta, K., Zawinka, C., Katamay, R., Flammer, J. \& Orgul, S. (2006). Short-term retinal vessel diameter variability in relation to the history of cold extremities. Investigative Ophthalmology and Visual Sciences, 47, 4026-4033.

Kölmel, H.W. (1985). Complex visual hallucinations in the hemianopic field. Journal of Neurology, Neurosurgery, and Psychiatry, 48, 29-38.

Konieczka, K. \& Erb, C. (2017). Diseases potentially related to Flammer syndrome. EPMA Journal, 8, 327-332. 
Konieczka, K. \& Flammer, J. (2016). Phenomenology and Clinical Relevance of the Flammer Syndrome. Klinische Monatsblätter für Augenheilkunde, 233, 1331-1336.

Konieczka, K., Ritch, R., Traverso, C.E., Kim, D.M., Kook, M.S., Gallino, A., Golubnitschaja, O., Erb, C., Reitsamer, H.A., Kida, T., Kurysheva, N. \& Yao, K. (2014). Flammer syndrome. EPMA Journal, 5, eCollection.

Konieczka, K., Koch, S., Binggeli, T., Schoetzau, A. \& Kesselring, J. (2016b). Multiple sclerosis and primary vascular dysregulation (Flammer syndrome). EPMA Journal, 7, 13.

Konieczka, K., Koch, S., Schoetzau, A. \& Todorova, M.G. (2016a). Increased Prevalence of Flammer Syndrome in Patients with Retinitis Pigmentosa. Klinische Monatsblätter für Augenheilkunde, 233, 448-452.

Konieczka, K., Todorova, M.G., Bojinova, R.I., Binggeli, T., Chackathayil, T.N. \& Flammer, J. (2016c). Unexpected Effect of Calcium Channel Blockers on the Optic Nerve Compartment Syndrome. Klinische Monatsblätter für Augenheilkunde, 233, 387-390.

Kupers, R., Beaulieu-Lefebvre, M., Schneider, F.C., Kassuba, T., Paulson, O.B., Siebner, H.R. \& Ptito, M. (2011). Neural correlates of olfactory processing in congenital blindness. Neuropsychologia, 49, 2037-2044.

Kurysheva, N.I., Ryabova, T.Y. \& Shlapak, V.N. (2018). Heart rate variability: The comparison between high tension and normal tension glaucoma. EPMA Journal, 9, 35-45.

Land, M.F. (2006). Eye movements and the control of actions in everyday life. Progress in Retinal and Eye Research, 25, 296324.

Lewis, P.M. \& Rosenfeld, J.V. (2016). Electrical stimulation of the brain and the development of cortical visual prostheses: An historical perspective. Brain Research, 1630, 208-224.

Longden, T.A., Dabertrand, F., Koide, M., Gonzales, A.L., Tykocki, N.R., Brayden, J.E., Hill-Eubanks, D. \& Nelson, M.T. (2017). Capillary K+-sensing initiates retrograde hyperpolarization to increase local cerebral blood flow. Nature Neuroscience, 20, 717-726.

MacAskill, M.R. \& Anderson, T.J. (2016). Eye movements in neurodegenerative diseases. Current Opinion in Neurology, 29, 61-68.

Mahler, F., Saner, H., Würbel, H. \& Flammer, J. (1989). Local cooling test for clinical capillaroscopy in Raynaud's phenomenon, unstable angina, and vasospastic visual disorders. Vasa, 18, 201-204.

Mann, L. (1904). Über elektrotherapeutische Versuche bei Optikuserkrankungen. Zeitschrfür diät phys Therapie, 8, 416427.

Marra, G. \& Flammer, J. (1991). The learning and fatigue effect in automated perimetry. Graefe's Archive for Clinical and Experimental Ophthalmology, 229, 501-504.

Marshall, R.S., Ferrera, J.J., Barnes, A., Zhang, X., O’Brien, K.A., Chmayssani, M., Hirsch, J. \& Lazar, R.M. (2008). Brain activity associated with stimulation therapy of the visual borderzone in hemianopic stroke patients. Neurorehabilitation and Neural Repair, 22, 136-144.

Martinez-Conde, S., Otero-Millan, J. \& Macknik, S.L. (2013). The impact of microsaccades on vision: Towards a unified the- ory of saccadic function. Nature reviews. Neuroscience, 14, 83-96.

Matteo, B.M., Viganò, B., Cerri, C.G. \& Perin, C. (2016). Visual field restorative rehabilitation after brain injury. Journal of Vision, 16, 11.

Mazzi, C., Savazzi, S. \& Silvanto, J. (2018). On the "blindness" of blindsight: What is the evidence for phenomenal awareness in the absence of primary visual cortex (V1)? Neuropsychologia, in press.

Meienberg, O., Flammer, J. \& Ludin, H.P. (1982). Subclinical visual field defects in multiple sclerosis. Demonstration and quantification with automated perimetry, and comparison with visually evoked potentials. Journal of Neurology, 227, 125-133.

Merabet, L.B. (2011). Building the bionic eye: An emerging reality and opportunity. Progress in Brain Research, 192, 3-15.

Merabet, L.B. \& Pascual-Leone, A. (2010). Neural reorganization following sensory loss: The opportunity of change. Nature Reviews. Neuroscience, 11, 44-52.

Merabet, L.B., Rizzo, J.F. 3rd, Pascual-Leone, A. \& Fernandez, E. (2007). 'Who is the ideal candidate?' Decisions and issues relating to visual neuroprosthesis development, patient testing and neuroplasticity. Journal of Neural Engineering, 4, S130135 .

Merabet, L.B., Rizzo, J.F., Amedi, A., Somers, D.C. \& PascualLeone, A. (2005). What blindness can tell us about seeing again: Merging neuroplasticity and neuroprostheses. Nature Reviews. Neuroscience, 6, 71-77.

Metz, G.A., Schwab, M.E. \& Welzl, H. (2001). The effects of acute and chronic stress on motor and sensory performance in male Lewis rats. Physiology \& Behavior, 72, 29-35.

Mills, J.O., Jalil, A. \& Stanga, P.E. (2017). Electronic retinal implants and artificial vision: Journey and present. Eye (London), 31, 1383-1398.

Morimoto, T., Miyoshi, T., Matsuda, S., Tano, Y., Fujikado, T. \& Fukuda, Y. (2005). Transcorneal electrical stimulation rescues axotomized retinal ganglion cells by activating endogenous retinal IGF-1 system. Investigative Ophthalmology and Visual Sciences, 46, 2147-2155.

Morris, S.L., Foster, C.J., Parsons, R., Falkmer, M., Falkmer, T. \& Rosalie, S.M. (2015). Differences in the use of vision and proprioception for postural control in autism spectrum disorder. Neuroscience, 307, 273-280.

Mozaffarieh, M., Schoetzau, A., Sauter, M., Grieshaber, M., Orgül, S., Golubnitschaja, O. \& Flammer, J. (2008). Comet assay analysis of single-stranded DNA breaks in circulating leukocytes of glaucoma patients. Molecular Vision, 14, 1584-1588.

Mozaffarieh, M., Fontana Gasio, P., Schötzau, A., Orgül, S., Flammer, J. \& Kräuchi, K. (2010). Thermal discomfort with cold extremities in relation to age, gender, and body mass index in a random sample of a Swiss urban population. Population Health Metrics, 8, 17.

Najarpour Foroushani, A., Pack, C.C. \& Sawan, M. (2018). Cortical visual prostheses: From microstimulation to functional percept. Journal of Neural Engineering, 15, 021005.

Ohl, S., Wohltat, C., Kliegl, R., Pollatos, O. \& Engbert, R. (2016). Microsaccades Are Coupled to Heartbeat. Journal of Neuroscience, 36, 1237-1241. 
Otto, J. \& Michelson, G. (2014). Repetitive tests of visual function improved visual acuity in young subjects. British Journal of Ophthalmology, 98, 383-386.

Owsley, C. (2011). Aging and vision. Vision Research, 51, 16101622.

Pache, M., Kräuchi, K., Cajochen, C., Wirz-Justice, A., Dubler, B., Flammer, J. \& Kaiser, H.J. (2001). Cold feet and prolonged sleep-onset latency in vasospastic syndrome. Lancet, $358,125-126$

Palva, J.M. \& Palva, S. (2017). Functional integration across oscillation frequencies by cross-frequency phase synchronization. European Journal of Neuroscience, in press.

Pammer, K. (2014). Temporal sampling in vision and the implications for dyslexia. Frontiers in Human Neuroscience, 7, 933.

Pardue, M.T. \& Allen, R.S. (2018). Neuroprotective strategies for retinal disease. Progress in Retinal and Eye Research, 65, 50-76.

Pascual-Leone, A., Amedi, A., Fregni, F. \& Merabet, L.B. (2005). The plastic human brain cortex. Annual Review of Neuroscience, 28, 377-401.

Pascolini, D. \& Mariotti, S.P. (2012). Global estimates of visual impairment 2010. British Journal of Ophthalmology, 96, 614618.

Plow, E.B., Obretenova, S.N., Fregni, F., Pascual-Leone, A. \& Merabet, L.B. (2012). Comparison of visual field training for hemianopia with active versus sham transcranial direct cortical stimulation. Neurorehabilitation and Neural Repair, 26, 616-626.

Poggel, D.A., Kasten, E. \& Sabel, B.A. (2004). Attentional cueing improves vision restoration therapy in patients with visual field loss. Neurology, 63, 2069-2076.

Poggel, D.A., Kasten, E., Müller-Oehring, E.M., Bunzenthal, U. \& Sabel, B.A. (2006a). Improving residual vision by attentional cueing in patients with brain lesions. Brain Research Cognitive Brain Research, 1097, 142-148.

Poggel, D.A., Müller-Oehring, E.M., Gothe, J., Kenkel, S., Kasten, E. \& Sabel, B.A. (2006b). Visual hallucinations during spontaneous and training-induced visual field recovery. $\mathrm{Neu}$ ropsychologia, 45, 2598-2607.

Polat, U., Ma-Naim, T., Belkin, M., Sagi, D. (2004). Improving vision in adult amblyopia by perceptual learning. Proc Natl Acad Sci USA, 101, 6692-6697.

Pöppel, E., Held, R. \& Frost, D. (1973). Residual visual function after brain wounds involving the central visual pathways in man. Nature, 243, 295-296.

Proudlock, F.A. \& Gottlob, I. (2007). Physiology and pathology of eye-head coordination. Progress in Retinal and Eye Research, $26,486-515$

Quigley, H.A. (2011). Glaucoma. Lancet, 377, 1367-1377.

Rachitskaya, A.V. \& Yuan, A. (2016). Argus II retinal prosthesis system: An update. Ophthalmic Genetics, 37, 260-266.

Reinhard, J., Schreiber, A., Schiefer, U., Kasten, E., Sabel, B.A., Kenkel, S., Vonthein, R. \& Trauzettel-Klosinski, S. (2005). Does visual restitution training change absolute homonymous visual field defects? A fundus controlled study. British Journal of Ophthalmology, 89, 30-35.
Röder, B., Stock, O., Bien, S., Neville, H. \& Rösler, F. (2002) Speech processing activates visual cortex in congenitally blind humans. European Journal of Neuroscience, 16, 930936.

Romano, J.G., Schulz, P. \& Kenkel, S. (2008). Visual field changes after a rehabilitation intervention: Vision restoration therapy. Journal of the Neurological Sciences, 273, 70-74.

Rosenberg, E.A. \& Sperazza, L.C. (2008). The visually impaired patient. American Family Physician, 77, 1431-1436.

Roth, T., Sokolov, A.N., Messias, A., Roth, P., Weller, M. \& Trauzettel-Klosinski, S. (2009). Comparing explorative saccade and flicker training in hemianopia: A randomized controlled study. Neurology, 72, 324-331.

Sabel, B.A. (1999). Restoration of vision I: Neurobiological mechanisms of restoration and plasticity after brain damage a review. Restorative Neurology and Neuroscience, 15, 177200 .

Sabel, B. (2016). Restoring Low Vision, Amazon, Charleston.

Sabel, B.A. \& Gudlin, J. (2014). Vision Restoration Training for Glaucoma. A randomized Clinical Trial. JAMA Ophthalmology, 132, 381-389.

Sabel, B.A., Fedorov, A., Henrich-Noack, P. \& Gall, C. (2011a). Vision restoration after brain damage: The "Residual Vision Activation Theory". Progress in Brain Research, 192, 199262.

Sabel, B.A., Wang, J., Cárdenas-Morales, L., Faiq, M. \& Heim, C. (2018). Mental stress as consequence and cause of vision loss: The dawn of psychosomatic ophthalmology - a review. EPMA Journal, 9, 133-160.

Sabel, B.A., Fedorov, A.B., Naue, N., Borrmann, A., Herrmann, C. \& Gall, C. (2011b). Non-invasive alternating current stimulation improves vision in optic neuropathy. Restorative Neurology and Neuroscience, 29, 493-505.

Sadato, N., Pascual-Leone, A., Grafman, J., Ibañez, V., Deiber, M.P., Dold, G. \& Hallett, M. (1996). Activation of the primary visual cortex by Braille reading in blind subjects. Nature, 380 , 526-528.

Sahraie, A., Trevethan, C.T., MacLeod, M.J., Murray, A.D., Olson, J.A. \& Weiskrantz, L. (2006). Increased sensitivity after repeated stimulation of residual spatial channels in blindsight. Proceedings of the National Academy of Sciences of the United States of America, 103, 14971-14976.

Samuels, B.C., Hammes, N.M., Johnson, P.L., Shekhar, A., McKinnon, S.J. \& Allingham, R.R. (2012). Dorsomedial/Perifornical hypothalamic stimulation increases intraocular pressure, intracranial pressure, and the translaminar pressure gradient. Investigative Ophthalmology and Visual Sciences, 53, 7328-7335.

Sanders, M.D., Warrington, E.K., Marshall, J. \& Weiskrantz, L. (1974). "Blindsight": Vision in a field defect. Lancet, 1, 707 708.

Schatz, A., Röck, T., Naycheva, L., Willmann, G., Wilhelm, B., Peters, T., Bartz-Schmidt, K.U., Zrenner, E., Messias, A. \& Gekeler, F. (2011). Transcorneal electrical stimulation for patients with retinitis pigmentosa: A prospective, randomized, sham-controlled exploratory study. Investigative Ophthalmology and Visual Sciences, 52, 44854496. 
Schoemann, J., Engelhorn, T., Waerntges, S., Doerfler, A., ElRafei, A. \& Michelson, G. (2014). Cerebral microinfarcts in primary open-angle glaucoma correlated with DTI-derived integrity of optic radiation. Investgative Ophthalmology and Visual Sciences, 55, 7241-7247.

Schultz, G. \& Melzack, R. (1991). The Charles Bonnet syndrome: 'Phantom visual images.' Perception, 20, 809-825.

Seiler, M.J. \& Aramant, R.B. (2012). Cell replacement and visual restoration by retinal sheet transplants. Progress in Retinal and Eye Research, 31, 661-687.

Shandurina, A.N. \& Panin, A.V. (1990). Clinical and physiological analysis of periorbital transcutaneous electrical stimulation method for damaged optic nerve and retina. Fiziologiia Cheloveka, 16, 53-59.

Shemagonov, A.V. \& Sidorenko, V.N. (2000). Can the Medical Resonance Therapy Music affect autonomous innervation of cerebral arteries? Integrative Physiological and Behavioral Science, 35, 218-223.

Shepherd, R.K., Shivdasani, M.N., Nayagam, D.A., Williams, C.E. \& Blamey, P.J. (2013). Visual prostheses for the blind. Trends in Biotechnology, 31, 562-571.

Shi, X.F., Xu, L.M., Li, Y., Wang, T., Zhao, K.X. \& Sabel, B.A. (2012). Fixational saccadic eye movements are altered in anisometropic amblyopia. Restorative Neurology and Neuroscience, 30, 445-462.

Shily, B.G. (1987). Psychophysiological stress, elevated intraocular pressure, and acute closed-angle glaucoma. American Journal of Optometry and Physiological Optics, 64, 866-870.

Silverstein, S.M. \& Rosen, R. (2015). Schizophrenia and the eye. Schizophrenia Research. Cognition, 2, 46-55.

Sossi, N. \& Anderson, D.R. (1983). Blockage of axonal transport in optic nerve induced by elevation of intraocular pressure. Effect of arterial hypertension induced by angiotensin I. Archives in Ophthalmology, 101, 94-97.

Stein, J. (2014). Dyslexia: The Role of Vision and Visual Attention. Current Developmental Disorders Reports, 1, 267-280.

Stevens, G.A., White, R.A., Flaxman, S.R., Price, H., Jonas, J.B., Keeffe, J., Leasher, J., Naidoo, K., Pesudovs, K., Resnikoff, S., Taylor, H. \& Bourne, R.R.A. (2013). Global prevalence of vision impairment and blindness: Magnitude and temporal trends, 1990-2010. Ophthalmology, 120, 2377-2384.

Stew, W.C. (1997). Chronic Open-angle Glaucoma and Lifestyle. Progress in Retinal and Eye Research, 16, 567-590.

Tan, C.S., Sabel, B.A., Goh, K.Y. (2006). Visual hallucinations during visual recovery after central retinal artery occlusion. Arch Neurol 63, 598-600.

Tang, Y.-Y., Holzel, B. \& Posner, M. (2015). The neuroscience of mindfulness meditation. Nature Review Neuroscience, 16, 213-225.

Tao, Y., Chen, T., Liu, Z.Y., Wang, L.Q., Xu, W.W., Qin, L.M., Peng, G.H. \& Yi-Fei, H. (2016). Topographic Quantification of the Transcorneal Electrical Stimulation (TES)-Induced Protective Effects on N-Methyl-N-Nitrosourea-Treated Retinas. Investigative Ophthalmology and Visual Sciences, 57, 4614-4624.

Uhlhaas, P.J. \& Singer, W. (2006). Neural synchrony in brain disorders: Relevance for cognitive dysfunctions and pathophysiology. Neuron, 52, 155-168. van Arb, M., Gompper, B., Meyer, A.H., Stutz, E.Z., Orgül, S., Flammer, J. \& Kräuchi, K. (2009). Relationship between gender role, anger expression, thermal discomfort and sleep onset latency in women. BioPsychoSocial Medicine, 3,11 .

Wang, J., Li, T., Sabel, B.A., Chen, Z., Wen, H., Li, J., Xie, X., Yang, D., Chen, W., Wang, N., Xian, J. \& He, H. (2016). Structural brain alterations in primary open angle glaucoma: A 3T MRI study. Science Reports, 6, 18969.

Whiting, P., Kerby, J., Coffey, P., da Cruz, L. \& McKernan, R. (2015). Progressing a human embryonic stem-cell-based regenerative medicine therapy towards the clinic. Philosophical transactions of the Royal Society of London. Series B, Biological Sciences, 370, 20140375.

WHO Fact Sheet. Visual impairment and blindness. Fact Sheet N 282, updated August 2014. http://www.who.

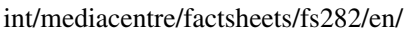

Williams, M.E., Fink, C., Zamora, I. \& Borchert, M. (2014). Autism assessment in children with optic nerve hypoplasia and other vision impairments. Developmental Medicine and Child Neurology, 56, 66-72.

Winterson, B.J. \& Collewijn, H. (1976). Microsaccades during finely guided visuomotor tasks. Vision Research, 16, 13871390.

Wostyn, P., Audenaert, K. \& De Deyn, P.P. (2010). Alzheimer's disease: Cerebral glaucoma? Medical Hypotheses, 74, $973-$ 977.

Yang, D., Fu, J., Hou, R., Liu, K., Jonas, J.B., Wang, H., Chen, W., Li, Z., Sang, J., Zhang, Z., Liu, S., Cao, Y., Xie, X., Ren, R., Lu, Q., Weinreb, R.N. \& Wang, N. (2014). Optic neuropathy induced by experimentally reduced cerebrospinal fluid pressure in monkeys. Investigative Ophthalmology and Visual Sciences, 55, 3067-3073.

Yeghiazaryan, K., Flammer, J., Orgül, S., Wunderlich, K. \& Golubnitschaja, O. (2009). Vasospastic individuals demonstrate significant similarity to glaucoma patients as revealed by gene expression profiling in circulating leukocytes. Molecular Vision, 15, 2339-2348.

Yin, H., Yin, H., Zhang, W., Miao, Q., Qin, Z., Guo, S., Fu, Q., Ma, J., Wu, F., Yin, J., Yang, Y. \& Fang, X. (2016). Transcorneal electrical stimulation promotes survival of retinal ganglion cells after optic nerve transection in rats accompanied by reduced microglial activation and TNF-alpha expression. Brain Research, 1650, 10-20.

Yu, L., Xie, B., Yin, X., Liang, M., Evans, A.C., Wang, J. \& Dai, C. (2013). Reduced cortical thickness in primary open-angle glaucoma and its relationship to the retinal nerve fiber layer thickness. PLoS One, 8, e73208.

Yücel, Y. (2013). Central nervous system changes in glaucoma. Journal of Glaucoma, 22, S24-25.

Zhang, X., Kedar, S., Lynn, M.J., Newman, N.J. \& Biousse, V. (2006). Natural history of homonymous hemianopia. Neurology, 66, 901-905.

Zhou, W.T., Ni, Y.Q., Jin, Z.B., Zhang, M., Wu, J.H., Zhu, Y., $\mathrm{Xu}$, G.Z. \& Gan, D.K. (2012). Electrical stimulation ameliorates light-induced photoreceptor degeneration in vitro via suppressing the proinflammatory effect of microglia and enhancing the neurotrophic potential of Müller cells. Experimental Neurology, 238, 192-208. 